University of Rhode Island

DigitalCommons@URI

Open Access Master's Theses

1999

\title{
Parental Socialization and the Child's Development of Internal Concepts of Self and Others
}

Elena Sylvie Mirsky

University of Rhode Island

Follow this and additional works at: https://digitalcommons.uri.edu/theses

\section{Recommended Citation}

Mirsky, Elena Sylvie, "Parental Socialization and the Child's Development of Internal Concepts of Self and Others" (1999). Open Access Master's Theses. Paper 1736.

https://digitalcommons.uri.edu/theses/1736

This Thesis is brought to you for free and open access by DigitalCommons@URI. It has been accepted for inclusion in Open Access Master's Theses by an authorized administrator of DigitalCommons@URI. For more information, please contact digitalcommons-group@uri.edu. 
PARENTAL SOCIALIZATION AND THE CHILD'S DEVELOPMENT OF

INTERNAL CONCEPTS OF SELF AND OTHERS

BY

ELENA MIRSKY

A THESIS SUBMITTED IN PARTIAL FULFILLMENT OF THE REQUIREMENTS FOR THE DEGREE OF MASTER OF ARTS

IN

PSYCHOLOGY

$$
\text { Y. } 02, \%
$$

THE UNIVERSITY OF RHODE ISLAND 
ABSTRACT
The process by which children develop internal models of the self and others has been an area of much theoretical interest. This study explored the influence of parental affective and verbal socialization messages as well as children's own mastery experiences on the child's emerging internal models of self and significant others. The goals of the study were to replicate the association between parental control style and child compliance as reported in the child development literature and to examine the relationship between child compliance and child self-concept. The sample studied consisted of 46 children and their mothers who participated in a larger longitudinal study of infant temperament involving assessments at infancy, $2 \frac{1}{2}$ years and 5 years of age. Child compliance scores were coded from a mother/child clean-up task at $2 \frac{1 / 2}{2}$ and 5 years. Maternal control scores were coded from a mother/child problem-solving task at $2 \frac{1}{2}$ years and from the clean-up task at $21 / 2$ and 5 years. The child self-concept scores were coded from a self-concept interview at 5 years. Bivariate correlations demonstrated some support for the distinction between child committed and situational compliance as discussed in Kochanska's (1995) work on child internalization and compliance. Support is similarly provided for the association between more committed forms of child compliance and more supportive, less controlling parenting styles. In the area of child self-concept, an association was demonstrated between children who display committed compliance and children who identified themselves as demonstrating more self control, suggesting support for future exploration into the role of child temperament as a potential mediating variable. 


\section{ACKNOWLEDGEMENT}

My work on this master's thesis project was inspired by my love of children as well as my admiration of and respect for the adventure of childhood. This interest revolves less around the nature of children's conformity to rules or obedience to their parents, and more to the complex and dynamic process through which children integrate the temperamental qualities within themselves and the environmental stimuli surrounding them to emerge as unique little personalities with distinct strategies and outlooks with which to approach their world. It is this process of the emerging person which fills me with constant wonder, and which I believe represents one of the most fascinating and important areas of psychological study.

I wish to express my gratitude to Laura Giusti, who not only laid the groundwork for this project, but without whose patience and support this process would have been much more harrowing. I also wish to acknowledge Dr. Graznya Kochanska, whose inspiration and support during this process was invaluable. I am equally indebted to $\mathrm{Dr}$. Ronald Seifer and Dr. Karin Magee at the Bradley Research Center, who were exceedingly generous with their data as well as with their support and expertise. I wish to also thank Dr. Allan Berman, who served as the advisor for this thesis project, and Dr. Paul DeMesquita and Dr. Margaret McGrath who served on my thesis committee. Finally, I must of course give thanks to my family and friends, you all know who you are, without whose love and support this child would not have emerged into the person she is today. 


\section{TABLE OF CONTENTS}

ABSTRACT

ACKNOWLEDGEMENT

TABLE OF CONTENTS iv

LIST OF TABLES V v

INTRODUCTION 1

Kochanska's theory of committed compliance 2

Competence and mastery 5

Development of self-concept $\quad 7$

$\begin{array}{ll}\text { Measurements used } & 10\end{array}$

PURPOSE OF STUDY 12

$\begin{array}{ll}\text { METHODS } & 14\end{array}$

$\begin{array}{ll}\text { Subjects } & 14\end{array}$

$\begin{array}{ll}\text { Procedure } & 15\end{array}$

$\begin{array}{ll}\text { Clean-up } & 15\end{array}$

Self-concept measure 16

$\begin{array}{ll}\text { Problem-solving measure } & 16\end{array}$

$\begin{array}{ll}\text { Coding systems } & 17\end{array}$

$\begin{array}{ll}\text { RESULTS } & 20\end{array}$

$\begin{array}{ll}\text { DISCUSSION } & 26\end{array}$

$\begin{array}{ll}\text { APPENDICES } & 34\end{array}$

$\begin{array}{ll}\text { Appendix } 1 & 35\end{array}$

Appendix 2 (Tables 1-4) 36

Appendix 3 (Compliance Coding Manual) 39

Appendix 4 (Eder Self-Concept Dimensions) $\quad 77$

$\begin{array}{ll}\text { BIBLIOGRAPHY } & 80\end{array}$ 


\section{LIST OF TABLES}

1. TABLE 1: Child Compliance at $2 \frac{1}{2}$ and 5 years of age

2. TABLE 2: Child Compliance and Parental Style

3. TABLE 3: Child Compliance and Child Self-Concept

4. TABLE 4: Parental Style and Child Self-Concept 


\section{INTRODUCTION}

For some time, researchers and theorists have been interested in the process by which children come to form internal models of the self and others that help guide the child through life. (Bowlby, 1979; Freud, 1959; Piaget, 1932). It is theorized that these internalized rules and standards for conceptualizing the self and how one interacts with others are communicated by the parent through both verbal and nonverbal socialization messages. While some have regarded this as a process of struggle for the parent against the child's own egocentric impulses (Freud, 1959), others have focused on the powerful influence of the parent-child relationship and the child's desire for closeness in motivating the child's internalization of the parental message (Maccoby, 1980). More recent work has focused on the significance of compliant behavior as a manifestation of the child's internal sense of social awareness and obligation (Kochanska et al, 1996), as well as on factors of child competence and mastery as they influence the emergence of a positive internal self-concept (Sroufe et al, 1978).

Current work in the area of child compliance has theorized that child compliance develops in the context of a supportive parent-child relationship. When the child completes a task as requested by the parent, the child receives positive feedback in the form of praise or positive evaluation. In addition, when compliant the child experiences the parent's happiness and satisfaction with the child. Over time and repeated parentchild interactions, the quality of the parent-child relationship, the child's repeated experience in interacting with the parent, and the associated shared affect are thought to become internalized by the child. That is, the process of internalization is achieved when the child can hold the image and feeling of the parent's responses within himself 
when not in the parent's immediate presence, and when completing the task produces positive feelings for the child without direct reinforcement from the parent.

The present study seeks to explore the process by which parental socialization messages influence the child's developing conceptualizations of himself and others. Through the communication of both verbal commands and nonverbal affective messages, as observed in contexts involving both teaching and behavioral commands, the parent is theorized to help nurture the child's positive inner models of the self. Similarly, these parental messages serve to foster the child's internal sense of social obligation as manifested through his outward compliance to social demands in such contexts as a cleaning task. Such a demonstration of successful internalization suggests one area of mastery which may in turn serve to support the child's growing sense of himself as a competent and worthwhile person, as examined through an exercise in selfdescription.

Kochanska's theory of committed compliance. Kochanska has operationalized the construct of internalization using the concept of committed compliance to represent the early stages in this process of moving from externally to internally regulated behavior (Kochanska \& Aksan, 1995, Kochanska et al, 1996). This categorization of compliant behavior is illustrated by the child "comply(ing) to parents wholeheartedly, with a feeling of internal commitment, fully endorsing and embracing the parental agenda as their own". Children with such commitment are characterized as displaying spontaneous self-corrections in the midst of transgressions without requiring outside intervention, as well as producing verbal indications of internal controls such as saying "no touch" when trying to resist tempting objects. Contrary to this committed form of 
compliance is what Kochanska has termed situational compliance. In the case of situational compliance, the cooperative and nonoppositional behavior displayed by the child would not be expected to persist after the parent has ceased to provide prompts. This form of compliance is typically regarded as less developmentally advanced, because it suggests a more externalized sense of conscience. The child requires constant parent direction and guidance in order to compensate for their own lack of internally guided direction and motivation. It is the subtle yet crucial distinction between these two types of compliant behavior which Kochanska believes best illustrates the stage to which the child has progressed at that time on the path to internalization, with all other observed behavior being characterized simply as noncompliant or defiant.

While compliance in these contexts is assessed as a characteristic of a particular child, it has also been understood to develop within the context of the parent-child relationship as influenced by the quality of the caregiver's control style (Maccoby \& Martin, 1983). Building upon the findings of earlier work examining the impact of parental discipline styles on child behavior (Hoffman, 1970; Sears, 1961), Kochanska has similarly explored the degree to which there is a particular aspect of the parent's style which influences the quality or nature of the child's compliant act. According to the attributional view of conscience development, a child's compliance to less powerassertive parental strategies is likely to be experienced as self-generated and to be associated with a feeling of internal commitment to the parental agenda (Kochanska, 1993). On the other hand, compliance to power-assertive strategies is more likely to be attributed to external contingencies and be more temporary or situational in nature 
(Lepper, 1981). Kochanska's work supports her assertion that the level of internalization achieved by the child, as manifested by the specific quality of the child's compliant behavior, involves the nature and degree of control used in the interaction with the child, particularly in contexts where they attempt to set an agenda for the child to complete a task. (Kochanska, 1987; 1991; 1995a; 1995b) While a parenting style which exhibits supportive guidance has been found to relate to the child's internalization of the parental agenda, those parents who display more forceful or threatening control styles have children who are more likely to exhibit more externalized forms of compliance.

As has been found in the past (Sears et al, 1953; Baumrind, 1973), Kochanska's work has demonstrated that power-assertive parenting styles involving forceful control through the use of physical punishment, intimidation or verbal threats are likely to accompany a more externalized manifestation of conscience in the child in the form of situational compliance (Kochanska et al, 1996; Kochanska, 1993). Kochanska posits that this form of compliance is not predictive of an emerging internalization and appears to be maintained purely by maternal control as opposed to the child being motivated by any sense of commitment to the parental agenda or any shared positive affect with the parent. On an observable level, the parental anger or punishment elicits anger and resentment in the child which leads them to reject the parental message. At the same time, the high level of arousal in the child which is elicited by the forceful assertion of the parental message exceeds a level that might otherwise serve to effectively motivate the child's behavior. This leads to difficulty for the child in processing the message in that the encounter becomes encoded in their episodic memory around the salience of the 
affect but is impaired from being processed semantically and integrated into their understanding of the experience. Thus, in future situations where compliance is demanded by the parent, the child re-experiences their negative affect associated with the experience in the form of anger, excessive anxiety or guilt, and performs the act of compliance solely in response to a parental demand rather than out of a feeling of internal commitment to the parental agenda or positive affect shared with the parent.

A more successful internalization of the parental agenda, as manifested through committed compliant behavior by the child, has been associated with a more gentle style of parental control as was shown by Kochanska in one study of 2-4 year olds who participated with mothers in both clean-up and prohibition tasks (Kochanska \& Aksan, 1995). Sometimes labeled "supportive presence" by Kochanska, this approach involves the parent using everything from reasoning and polite requests to positive comments and playful encouragements in a manner that creates a positive environment and encourages the child to want to be compliant. This combination of more relaxed control and shared positive affect with the child is thought to facilitate the internalization process through the elicitation of committed compliance. At the same time, Kochanska has recognized that the interplay between child temperament characteristics and parental style in this process is relatively complex in that child factors are theorized to mediate which of these two components of the parental message will be most instrumental in fostering internalization (Kochanska, 1993).

Competence and mastery. While the child's display of committed compliance can be regarded as a successful internalization of the parental agenda, it can similarly be viewed within the context of the child progressively acquiring various domains of 
competence (Seifer, 1998). The construct of competence, as defined by "the child's ability to use multiple behavior systems effectively in the face of developmental changes" (Seifer \& Vaughn, 1995), is conceptualized as emerging out of the socialization environment and as providing an organizational framework for the child's awareness about and interactions with the world. Much of the current work in this area has revolved around the mastery motivation construct, which focuses less on the achieved success of the child within a particular task and more on the child's persistence and attention towards some self-constructed and self-directed goal (BuschRossnagel et al, 1995). The primary components of mastery motivation include the provision of toys and objects by the caregiver, social stimulation stemming from the affective exchange between mother and child and didactic interchanges in the form of the parent scaffolding their child's learning experiences. Research in this area has indicated a negative relationship between parents who are overly directive and children's task persistence and pride in mastery attempts, suggesting that such children may learn to efficiently respond to the environment but not to effectively initiate interactions with it. Similarly, mastery motivation has been found to function within several domains of competence that emerge within the first few years of life, including the development of attachment relationships, the development of affect self-regulation, the development of peer relationships, cognitive development and task success, and the development of ego-control and ego-resiliency.

Competency research has similarly focused on the style of parental interaction as an important factor in the child's development of a sense of personal competence or self-efficacy. Theorists have explored the roles of parental warmth and discipline, as 
well the importance of a secure parent-infant attachment relationship in the fostering of child competence (Baumrind, 1973; Bowlby, 1979; White, 1975). More recent work has also recognized the impact of parental competence on their child's developing competence. Research conducted within the context of a problem-solving task has suggested that parental competence positively influences the degree to which parents expect their child to actively contribute to the solution, offer fewer commands and physical intrusions, show increased warmth, provide verbal and nonverbal indications of approval and offer more helpful problem-solving suggestions (Mondell \& Tyler, 1981).

Development of self-concept. Through the mechanism of parental socialization, the child is theorized to not only gain an understanding of the rules of social discourse, but also to incorporate their awareness of this and other domains of competency into their internal concept of the self. An early model of self-development was presented through Cooley's (1902) characterization of the "looking-glass-self", where the caregiver was conceptualized to serve as a "social mirror" through which the child would become aware of how they were evaluated by others and would then incorporate these evaluations into their sense of self. This conceptualization of the self as a social construction derived from verbal, affective and behavioral interactions with others was initially adopted by a group of theorists commonly labeled symbolic interactionists (Harter, 1998), and later by other theorists interested in the study of self-development. Winnicott (1958) described the concept that the caregiver's overall responsiveness to infant demands served to engender the child with a sense of personal power and competence that would facilitate development of a positive sense of self. Similarly, 
Bowlby (1969) believed that parents who were perceived by their children as loving, supportive and emotionally available would foster the child's construction of a working model of the self as lovable and competent. These concepts are comparable to those espoused by current attachment theorists in which the internalization by the infant of the newly developed working model of the relationship precedes other working models of self or caregiver (Cassidy, 1990, Sroufe, 1990). This process is theorized to subsequently empower the infant by providing a sense of control and self-regulation even when the parent is not present (Emde, 1988; Bretherton, 1991).

Contemporary research examining the development of the self and self-esteem continues to support the crucial role played by parent-child interactions in providing links between the communication of parental warmth, affection, responsiveness and support as well as the establishment of a secure attachment relationship for the child's development of a positive sense of self (Harter, 1998; Coopersmith, 1967; Bretherton, 1991). Other research has examined the impact of varying parenting styles on the emergence of a sense of self. In his now classic study of parenting styles, Baumrind found that competent children were more likely to have nurturant and involved parents who consistently encouraged and rewarded self-control and that power assertion by parents led to "the undermining of the child's development of a healthy and autonomous self- concept based on a conviction of personal worth"(Baumrind, 1967; Baumrind \& Black, 1967). While many theorists have supported this conclusion (Radke, 1946; Baldwin, 1948; Qadri \& Kaleem, 1971; Apolonio, 1975; Loeb et al, 1980) some findings have emerged as somewhat discrepant by supporting the influence of firm control by parents (Coopersmith, 1967; Comstock, 1973) on positive self- 
development. A consensus does seem to have been reached among these theorists, however, that less coercive and more democratic parenting approaches are the most crucial for successfully fostering high self-esteem and a positive sense of self.

The child's self-concept is traditionally operationalized as a set of stable characterizations the child makes about the self which develops from the child's growing awareness of himself as separate and gradual ability to label the emotions he experiences as well as those observed in others (Harter, 1983, 1998; Damon \& Hart, 1988). The child's early dispositional statements about self are commonly made in terms of specific instances rather than generalizations and typically refer to physical characteristics or activities rather than emotional states or feelings. Recent work in this area by Rebecca Eder $(1997,1987)$ has suggested that children move beyond this stage of concrete conceptualization to form organized and coherent self-concepts much earlier than was previously thought. She attributes this change to limitations in previous research instruments that were either too rigid or too open-ended to fully capture the child's language-comprehension and thus did not allow the child to fully express his thoughts. Eder has demonstrated that by the age of $3 \frac{1 / 2}{2}$ to 4 , many children are able to appropriately respond to general inquiries with general statements about behavior and are able to provide content-specific responses when asked either about feelings or actions. The generality of their responses suggest that these children have developed some basic dispositional concepts of how they and others typically behave which form the basis of a true self-concept

Eder stresses that the responses provided by children in her studies do not necessarily measure their actual behaviors but rather reflect their perceptions and 
concepts of what for them is typical behavior, whether it be accurate or not. Even more importantly, it must be remembered that the self-statements provided in this measure by children pertain simply to behaviors and consistent ways of acting rather than more global assignments of value to these behaviors or what the behaviors say about the child. Although the child is undoubtedly able to both mimic and hold onto positive evaluative statements made about him by parents or other adults and is hypothesized to slowly incorporate these statements into his own positive conceptualization of himself and his value as a person, research within the field has demonstrated that a fully integrated set of dispositional self-concepts including an assignment of self-worth or self-esteem does not fully emerge until age 7 or 8 . Thus based on the Eder measure it cannot be determined, but only inferred, that a child who endorses primarily positive behavior patterns and conceptualizes himself as being a "good boy" will gradually synthesize these two constructs into the conclusion that "I embody these positive qualities, therefore I am a good person".

Measurements used. Many of the methods commonly employed by Kochanska and others in the field to explore conscience development are reminiscent of those that have remained in use over the decades, and each provides a unique context within which to measure various manifestations of compliance. In situations such as the present study that examine the child's performance of desired behavior or compliance with direct requests, commonly labeled a "Do" task, the most frequently used method involves requiring the child to put away toys. Although such a cleanup task may be observed within the child's home, this task is frequently simulated within the laboratory with a period of mother-child free play being followed by a request by the experimenter 
that the mother have the child put all of the toys away. Kochanska has developed a coding system, which has been subsequently revised (Giusti et al, 1997), that involves breaking each task into 15 -second segments which are then coded for the predominant quality of the child's displayed compliance or noncompliance, as well as measures of the quality of the maternal control, quality of mother assistance, level of mother supportive presence and degree of mother assistance (see Appendix 3). Within this context, Kochanska describes committed compliance as being illustrated by the child staying willingly on task, progressing spontaneously from toy to toy, making verbal comments about her commitment to the task (i.e. "I'm a good cleaner-upper") and not stopping her cleaning even if the mother ceases to provide external interventions or encouragement.

As a means of assessing consistent and meaningful individual differences in young children's self-concepts, Eder has developed a measure involving a forcedchoice recognition task through which children present statements about themselves (Eder, 1989, 1990). The task employs a videotape of two puppets who describe themselves by each alternately stating the high and low side of a dimension ("I usually play with friends" or "I usually play by myself"). The child is then asked to indicate which puppet he is more like. Distinct dimensions comprising self-concept (see Appendix 4) have emerged from the measure varying by age (e.g. 31/2 year old factors include: self-control, general self-acceptance and rejection; 5 year old factors include: self-control, self-acceptance via achievement and self-acceptance via affiliation; and 7 year old factors include emotional stability, extraversion and determined fearlessness). Within this study, the problem-solving paradigm is not employed as a measure 
of child mastery motivation but rather as an opportunity to observe the mother's behavior within a context where the parent-child interaction is not explicitly directed around the maternal agenda. A coding system developed by Sroufe (1983) examines the mother's contribution to the interaction by rating her behavior on scales of quality of assistance and supportive presence. While quality of assistance examines the sensitivity and skill with which the mother helps her child learn concepts to solve the problem at hand, supportive presence measures the degree to which the mother provides emotional support to help create a positive experience for the child.

\section{PURPOSE OF STUDY}

Through the communication of verbal and nonverbal socialization messages from the parent, the child is theorized to develop stable internal models of the self and others. These internal representations serve to support the child as a social being through their interactions with the world, as well as bolstering their sense of self as a good and competent person. This study seeks to explore the influence of parental affective and verbal messages on the child's emerging internalization, and to examine whether different experiences of mastery lead to a correspondence between positive internal models of significant others and the self.

1. The first goal of the proposed study is to replicate the association between parental control style and child compliance established by Kochanska. This study would expand on previous work by allowing an examination of parental control style within two contexts; a clean-up task where the parent establishes the clean-up agenda 
with which the child is expected to comply, and a problem-solving task where there is no established parental agenda and the parent is expected to support the problemsolving efforts of their child. This examination would include using the measures of parental control from both the clean-up and problem-solving tasks at age $2 \frac{1}{2}$ years and from the clean-up task at 5 years to predict the child's committed compliance score from the clean-up task at 5 years.

Measures employed in this comparison would include the parental control measures from the problem-solving task of quality of parental assistance and supportive parental presence, and those from the clean-up task which would include comparable quality of assistance and supportive presence measures as well as parental control scores based on Kochanska's coding system. The compliance measures used in this comparison would originate from the clean-up task and would also be based on Kochanska's coding system.

2. The second goal of the study is to explore the possible relation between child's committed compliance and self-concept, with both constructs based in the child's construction of stable, internal models. It is hypothesized that a child who has internalized a positive working model of the parent will similarly have constructed a positive working model of himself. Thus, those children who wholeheartedly endorse the parental agenda by exhibiting committed compliance are expected to also endorse more self-concept statements regarding behaviors which are consistent with compliance such as traditionalism, achievement, social-potency and well-being. For example, children who display committed compliant behavior would be theorized to obtain higher scores on the self-control and self-acceptance subscales of the self-concept scale. 
The process of exploring this association would involve comparing their compliance scores from the clean-up tasks at age $21 / 2$ years and 5 years to their self-concept scores at 5 years.

Measures employed for this comparison would include self-concept measures based on the 5-year scales of self-control, self-acceptance via achievement and selfacceptance via affiliation from the Eder measure (see Appendix 4). Compliance measures based on Kochanska's coding system would be obtained from the clean-up task..

3. The third goal is to examine whether parental control style has an influence in predicting the child's subsequent self-concept, based on theories suggesting the influence of less-controlling parenting behaviors on positive self-development. It is hypothesized here that a supportive parental control style is one of the factors contributing to fostering the child's positive concept of himself as manifested through behaviors demonstrating such experiences as well-being, social closeness and achievement. This would involve examining parental control scores from the problemsolving and clean-up tasks from $2 \frac{1}{2}$ years, combined with the clean-up task from 5 years, to predict to child self-concept scores at 5 years.

This comparison would employ the parental control measures from both the problem-solving and clean-up tasks as mentioned above. The self-concept measures used would be those from the 5-year scales of the Eder measure as mentioned above. 


\section{METHOD}

Subjects

The original study consisted of 50 families who were initially recruited to participate in a longitudinal study to examine infant temperament during the first year of life. Families were recruited during the lying-in period at the university obstetrics hospital in Rhode Island. In an effort to select families so that contextual variables would be minimized, mothers were directly contacted who were white, not receiving public assistance, first-time mothers, and 20 years of age or older. About $15 \%$ of these families met the further criteria of the mother not intending to work full-time during the infant's first year and the infant's biological father living at home. After a brief explanation of the study and a period of two months to consider participation, about $50 \%$ of the remaining mothers agreed to participate. It should be noted that this recruitment strategy produced a final sample that was relatively affluent, intact, homogeneous and motivated to commit to an intensive longitudinal study.

The initial sample consisted of 24 boys and 26 girls, all of whom were first born. Forty-six children were followed and reassessed at the age of two and a half years and again between the ages of four and five years of age. The families were middle and working class with a Hollingshead (1975) four-factor SES average of $1.96(\mathrm{SD}=.75$, range 1-4). The study consisted of intact families, with the exception of one mother who was unmarried but had an ongoing relationship with the baby's father. The average age of the mothers was 29.1 years ( $\mathrm{SD}=4.2$, range 22.2-36.9) on the child's day of birth. 


\section{Procedure}

The present study is a small part of a larger longitudinal project which involved an initial assessment at 4 months to 14 months and then again at $21 / 2$ years and 5 years (see Appendix 1).

Clean-Up. The mother and child participated in a clean-up task at $2 \frac{1}{2}$ years and 5 years. Following a free play period, the experimenter entered the room with a large empty crate and provided the following instructions to the mother: "Now I'd like you to have (Child) clean up the toys. I'll be back when you're done." The mother and child were then left alone in the room and their interaction was videotaped through a one-way mirror. The experimenter returned to the room when the task had been completed or after a period of three minutes had passed.

Self-Concept Measure. The Eder self-concept measure was completed by the child at five years of age. The experimenter and child remained in the room while the mother left to participate in a separate interview. Two chairs were placed in front of a television and a tape appropriate for the child's gender was placed in the VCR. The experimenter and child were seated and the experimenter provided the following instructions: "We are going to watch a video about two puppets. They want to write a story about kids your age. They want to learn all about you. They are going to tell you about themselves and then you tell them about yourself. Are you ready?" The child then responded verbally with self-statements after being prompted by the puppets. The experimenter then began the tape and the child was expected to respond verbally with self-statements after being prompted by the puppets. If the child appeared to understand the two practice items the experimenter provided positive feedback to the child ("That's 
just how you play!"). If the child did not respond immediately after the prompt, the experimenter stopped the tape and restarted it once the child had answered. Children could be given a prompt to respond from the experimenter such as "How about you?" Children's responses were recorded on the scoring sheet and responses that differed from those of the puppets were recorded verbatim. The procedure was also videotaped through a one-way mirror. This measure has been shown to be internally consistent with high alpha coefficients (.75 for $3 \frac{1}{1 / 2}$-year-olds, .78 for $5 \frac{1}{1 / 2}$-year-olds and .78 for 7 $1 / 2$-year-olds) and to show test-retest reliability after one month (.47 for $31 / 2$-year-olds, .60 for $51 / 2$-year-olds and .65 for $7 \frac{1}{2} 2$-year-olds; Eder, 1990). Validity ratings were not available from other studies using this self-concept measure.

Problem-Solving Measure. The mother and child completed the problemsolving measure at $2 \frac{1}{2}$ years. The experimenter would enter the room with the first task and provide the mother with the following instructions: "The next few things we bring in are mostly for (Child) to do but you can give him/her whatever help he/she needs." The mother is also given a card which describes the solution to the task. The experimenter then turns to the child and says "See this toy, this is for you to get out and then you can take it home with you. I'll be back in when you're done." The first task consisted of a small toy placed in the center of a long plastic tube. It was accompanied by a long wooden stick which the child could use to push out the toy. The second task consisted of a similar set up but was accompanied by two short wooden the sticks. Neither stick was long enough to reach the toy but both sticks could be put together to push out the toy. The third task involved a small toy placed on a lever that extends inside a large plexiglass box. It was accompanied by a large "brick". Pushing on the 
lever raised the toy to the top of the box, but the child was required to use the brick to hold down the lever so that they could retrieve the toy. The experimenter allowed up to five minutes for completion of the first task and ten minutes for completion of the second and third tasks before entering the room. In those instances where the task was not completed, the experimenter would assist the child in retrieving the toy.

Coding Systems. Kochanska has developed a coding system, which has been subsequently revised (Giusti et al, 1997), that allows scoring of both child compliance and parental control behaviors. Clean-up sessions are initially rated for consistency of examiner instruction. The session is then broken up into 15 -second segments, each of which is coded for the predominant quality of the child's compliance and the parental control style, the presence of maternal physical control behaviors, maternal adherence to the clean-up agenda, the incidence of maternal positive or negative evaluations of the child, as well as overall ratings of the quality of mother assistance, level of mother supportive presence and degree of mother physical participation (see Appendix 3 for descriptions). Child compliance behaviors are rated on a continuum of committed compliance, situational compliance, passive non-compliance, overt non-compliance and defiance, with the presence of resistant or defiant behavior taking precedence over all other codes. The maternal control behaviors are rated on a continuum from social exchange and gentle guidance to control to forceful, high power control with the presence of negative control behaviors taking precedence over all other codes. Within this context, Kochanska describes committed compliance as being illustrated by the child staying willingly on task, progressing spontaneously from toy to toy, making verbal comments about her commitment to the task (i.e. "I'm a good cleaner-upper") 
and not stopping her cleaning even if the mother ceases to provide external interventions or encouragement. Interrater reliability coefficients of .80 and higher were established for this coding system using intraclass correlations.

The coding system for scoring the mother-child interaction within the context of the problem-solving situation was adapted from a system developed by Sroufe (1983). He focused on two aspects of the mother's contribution to the interaction: quality of assistance and supportive presence. Quality of assistance involves the sensitivity and skill with which the mother facilitates the child learning rules and concepts pertaining to the problem at hand that may later be generalized to other problems. Supportive presence refers to the level of emotional support provided by the mother to make the learning experience positive and enjoyable for the child, and to provide a secure base from which the child may act autonomously. Ratings are based on a continuum, with low scores indicating less successful maternal behaviors and high scores more appropriate and supportive maternal behaviors. An attempt is made to determine mother ratings independent of the child's behavior so that the focus remains on how she deals with the child at that particular moment and whether she reacts to the child's behavior in the most successful way possible. Interrater reliability coefficients of .80 and higher were established for this coding system using intraclass correlations. 


\section{RESULTS}

Question 1: The association between parental style and child compliance behavior

It was hypothesized that the present study would replicate the work of

Kochanska in demonstrating that mothers whose children exhibited higher levels of committed compliance would exhibit a more supportive, less controlling parental style.

Standard bivariate correlations were performed to explore this relationship for both concurrent parent and child measures as well as across two time periods (age $2 \frac{1}{2}$ and 5 years).

As a preface to the first question, Kochanska's demonstration of a clear distinction between more committed and situational forms of child compliance behavior was supported by this study at both $21 / 2$ years and 5 years (see Table 1). Demonstrated correlations were $-.65(p<.01)$ and $-.80(p<.01)$ respectively. Some correspondence was shown between children's demonstrated compliance at the two time points. While child Committed Compliance at $2 \frac{1}{2}$ years was found to be negatively associated with non-compliance at 5 years $(-.38, p<.05)$, child non-compliance at $21 / 2$ years was found to be positively correlated with higher non-compliance scores at 5 years. Minimal consistency was demonstrated between ratings of parental behavior at the two time points. Parents with higher scores on Quality of Assistance at 5 years were found to have demonstrated significantly higher scores on Supportive Presence and a significantly lower Level of Involvement at $2 \frac{1}{2}$ years $(.32, p<.05 ;-.35, p<.05)$.

At $2 \frac{1}{2}$ years of age, the committed form of child compliance was found to be positively associated with concurrent parental demonstrations of support (see Table 2) 
as measured by high scores on the Quality of Assistance and Supportive Presence scales from the clean-up task as well as the number of Positive Evaluations (e.g. 'you're a good cleaner-upper")expressed $(.40, \mathrm{p}<.01 ; .48, \mathrm{p}<.01 ; .47, \mathrm{p}<.01$ respectively). A negative relationship was demonstrated between committed compliance and a forceful parenting style $(-.31, \mathrm{p}<.05)$ as well as with a high level of maternal physical involvement $(.48, p<.01)$. Situational compliance at $2 \frac{1}{2}$ years was found to be positively correlated with a more Forceful parental style $(.43, \mathrm{p}<.01)$ and to be negatively associated with Positive Evaluations by the parent $(-.41, \mathrm{p}<.01)$. High scores on child non-compliance at $2 \frac{1}{2}$ years were found to be positively associated with increased levels of Parental Involvement and Gentle Physical contact and to be negatively related to higher levels of maternal Quality of Assistance and Supportive Presence (see Table 1). Child non-compliance was also found to be negatively correlated with the Maternal Support scale from the problem-solving task at $2 \frac{1}{2}$ years (see Table 1). Although the parental scale of Supportive Presence was found to correlate positively with maternal Gentle Guidance at $2 \frac{1}{2}$ years $(.54, \mathrm{p}<.01)$ and negatively with maternal Control $(-.46, p<.01)$, the results of the present study did not replicate Kochanska's association between child Committed Compliance and maternal Gentle Guidance.

Comparable associations between child compliance and parental style were demonstrated at 5 years of age (see Table 2). Higher levels of child Committed Compliance were associated with higher ratings of maternal Quality Assistance and Supportive Presence from the clean-up task at 5 years $(.53, \mathrm{p}<.01 ; .31, \mathrm{p}<.05)$. Committed Compliance was also found to be negatively related to increased levels of 
maternal Level of Involvement $(-.41, p<.01)$. At 5 years, none of the associations between Situational Compliance and the parental scales were found to be statistically significant. Child non-compliance at 5 years demonstrated a positive association with increased maternal Level of Involvement $(.32, \mathrm{p}<.05)$ and negative associations with maternal Gentle Guidance and maternal Quality of Assistance (see Table 2).

Although numerous associations between child compliance and parental style were demonstrated concurrently, parental style at $2 \frac{1}{2}$ years was found to be only minimally related to child compliance scores at 5 years. A higher number of maternal negative evaluations of the child and increased maternal Level of Involvement at $21 / 2$ years were found to be positively associated with higher levels of child Passive NonCompliance at 5 years $(.37, \mathrm{p}<.05 ; .33, \mathrm{p}<.05)$. Higher ratings of maternal Quality of Assistance at $2 \frac{1}{2}$ years were found to negatively relate to increased child Passive NonCompliance at 5 years $(-.38, \mathrm{p}<.05)$.

Question 2: The relationship between child compliance and child self-concept

The second focus of the study involved the relationship between demonstrated child compliance behaviors at both time points and child self-concept measured at 5 years of age. It was hypothesized that higher levels of observed child committed compliance from the clean-up task would be associated with children more often endorsing behaviors characteristic of themselves related to enhanced self-control and positive self-acceptance. Although no statistically significant relationships were demonstrated at $2 \frac{1}{2}$ years between child Committed Compliance and any of the SelfConcept dimensions, several significant associations emerged with the other forms of 
child compliance (see Table 3). At $2 \frac{1}{2}$ years, child Situational Compliance was found to be negatively associated with Traditionalism (-.33, $\mathrm{p}<.05)$, one of the sub-scales characterizing the positive end of the Self-Control dimension. Child Defiance at $2 \frac{1}{2}$ years was found to be negatively related to Harm-Avoidance $(-.33, \mathrm{p}<.05)$, also characterized on the positive end of the Self-Control dimension. One puzzling set of results which emerged involved the sub-scale of Social Closeness, which was found to be negatively associated with Passive Non-Compliance $(-.51, \mathrm{p}<.01)$ but positively associated with child Defiance $(.36, \mathrm{p}<.05)$.

Comparable results were found concurrently between child compliance and child self-concept (see Table 3). At 5 years, higher scores on the Traditionalism subscale were found to be positively correlated with increased levels of child Committed Compliance $(.34, \mathrm{p}<.05)$ and negatively correlated with child Situational Compliance ($.33, \mathrm{p}<.05)$. Higher scores on the Harm-Avoidance sub-scale were associated positively with a composite of child Committed and Situational Compliance (.40, $\mathrm{p}<$ $.05)$ and were negatively associated with Overt Non-Compliance at 5 years $(-.37, p<$ .05). The composite of child Compliance was also found to be negatively associated with higher scores on Aggression (-.32, $\mathrm{p}<.05)$, one of the subscales characterizing the negative end of the Self-Control dimension. Apart from the sub-scales from the SelfControl dimension of the self-concept measure, the only other significant correlation was between perceived Social Closeness and child Defiance at $21 / 2$ years of age (.36, $\mathrm{p}<.05)$. 
Question 3: The association between parental style and child self-concept

The third focus of the study explored the association between parenting style measured from the clean-up task at both time points and child self-concept measured at 5 years (see Table 4). It was hypothesized that a more supportive, less controlling style of parenting would be associated with children more often endorsing those characterizations of themselves which derived from the Self-Control and SelfAcceptance factors of the self-concept measure. Higher maternal Level of Involvement at $2 \frac{1 / 2}{2}$ years was negatively associated with higher child scores on the Harm-Avoidance sub-scale(-.32, $\mathrm{p}<.05)$. Increased incidence of maternal Distal Physical Control was negatively associated with higher scores of Harm-Avoidance $(.34, \mathrm{p}<.05)$. The maternal Quality of Assistance measure from the problem-solving task at $2 \frac{1}{2}$ years was found to correlate negatively with the Social Potency sub-scale $(-.41, \mathrm{p}<.05)$.

At 5 years, higher levels of maternal Quality of Assistance were found to be positively associated with higher scores on the Harm-Avoidance sub-scale $(.46, \mathrm{p}<.05)$. Higher levels of maternal Assertive Physical Control were positively associated with higher scores on the Aggression sub-scale $(.40, \mathrm{p}<.05)$ and with higher scores on the Social Potency sub-scale $(.35, \mathrm{p}<.05)$. Higher incidence of maternal Distal Physical Control was positively related to higher scores on Traditionalism $(.37, \mathrm{p}<.05)$. Increased maternal Level of Involvement at 5 years demonstrated a negative relationship with higher scores on Harm-Avoidance $(-.35, \mathrm{p}<.05)$.

Taken together, these results support an association between parental socialization practices and children's demonstrated behavior as well as their perceptions of their own behavior. A more supportive parental style was related to increased child 
committed compliance and to child perceptions of themselves as demonstrating more self-control behaviors. A more forceful or intrusive parental style was found to relate to more situational child compliance behaviors and child noncompliance as well as to child perceptions of the self as demonstrating more aggressive and less self-control behaviors. Similarly, child compliance behaviors were found to be associated with child self-concept. Those children who demonstrated increased committed compliance behaviors were more likely to endorse perceptions of themselves as exhibiting selfcontrol, while noncompliant children more often perceived themselves as aggressive and as demonstrating less self-control behaviors. 


\section{DISCUSSION}

\section{Parental socialization and compliance}

An association was clearly established between the style of parenting employed within a compliance situation and the nature and degree of child compliance behavior. Those mothers who relied on less controlling, more supportive means of eliciting compliance were more likely to have children who demonstrate not only a higher degree of compliance, but who also display a greater commitment to following the maternal agenda. The two parental ratings which emerged as most consistently associated with child compliance were the Quality of Assistance and Supportive Presence scales. This suggests that the sensitivity and skill with which the mother facilitates child learning in the compliance situation and the level of emotional support provided by the mother in that context are important factors in the development of internalization as manifested by compliance. The amount of physical involvement by the mother also appeared to be highly related to child compliance. With the exception of distal gestures by the mother (e.g. pointing to toys), the greater the amount of physical contact by the mother, the less compliance was demonstrated by the child. Physical contact in this case included the mother handing a toy to a child, touching the child in a gentle or forceful manner or participating in much of the cleaning task on their own. This finding suggests that some degree of child autonomy, as provided by the parent, is necessary to support the child's internalization of the parental demand. Although the ratings of maternal style of control within the clean-up task were significantly correlated with the Quality of Assistance and Supportive Presence scales, 
they demonstrated very few significant relationships with observed child compliance. This overall lack of association between Gentle Guidance and child Committed Compliance was surprising, especially considering the support for this relationship demonstrated by Kochanska (1995). It is noted, however, that Kochanska produced this association based on assessments across multiple contexts and that parental Gentle Guidance did not significantly correspond to child Committed Compliance in every setting. It is also noted that the present study employed less than half the sample size as that of Kochanska (46 vs. 103), which may account for the lack of significant results.

The predicted association between parental style employed at $2 \frac{1}{2}$ years and later demonstrations of child compliance received only moderate support in the current study. While Passive Non-Compliance behavior at 5 years was found to relate to several parental constructs from the $2 \frac{1}{2}$ year assessment, no early measures of parental style were found to be significantly associated with demonstrated child Committed Compliance at a later age. While it is possible that the small sample size failed to support significant correlations in this area, these results also highlight a number of important factors including the difficulty in predicting behavior from one time point to the next. The complex nature of measuring any developmental construct such as compliance involves many mediating variables that could be both directly and indirectly influencing its manifestation, thus making any claims of causality or prediction precarious at best. Another major consideration for predicting compliance behavior in the current study involves the use of only one context at each time point to measure both child compliance and parental control strategies. Common sense suggests that based on the potential variability of both child and parent behavior within different 
contexts or over different periods of time, the present study provides only a snapshot of the parent-child interaction. The present study is limited in that there was an absence of other contexts or assessment points to spread out the influence of potential bias.

The overall lack of consistency of parental style demonstrated over time in the present study highlights yet another consideration regarding the use of multiple assessments and contexts. The particular importance of assessing multiple contexts in compliance research is addressed in the work of Grusec \& Goodnow (1994) who find that there is commonly a lack of uniformity in parenting styles and disciplinary practices across contexts or situations. While they believe that children assess and respond to the relative fairness of parental demands within each particular situation, thus providing an alternative to Kochanska's mechanism of internalization in the development of the child's morality, Grusec \& Goodnow reinforce the importance of maintaining an awareness of the variability in both child and parent behavior across time and settings.

While the children in this study demonstrated a moderate consistency in compliance behavior over time, it was of interest that there was not the anticipated increase in child compliance from $2 \frac{1}{2}$ years to 5 years as described by Kochanska (1995). Kochanska does note, however, that this age trend was more marked in compliance tasks involving parental prohibition of behavior rather than those requiring behavioral responses to parental demands. While committed compliance as a manifestation of internalization is theorized to emerge gradually as a developmental process, this demonstrated lack of increased compliance with age reinforces the notion that there are multiple developmental requirements competing with compliance as the 
child matures. Crockenberg and Litman (1990) have indicated through their work that positive parenting behaviors correspond to both greater child compliance and greater self-assertive behaviors, suggesting that defiance, compliance and self-assertion might form distinct dimensions in a model of child behavior. Based on observations of compliance in the context of research on attachment, competence and emotional development, Sroufe et al (1978) have suggested that the truly competent child will commonly display some initial degree of noncompliance in response to parental demands. When followed by a demonstration of compliance, this initial display of oppositional behavior is regarded as an age appropriate indication of increasing child autonomy and adaptiveness. One means of exploring this age trend in the future might be to determine the ratio of child compliance to non-compliance behaviors separately for the beginning segment of the clean-up task.

\section{Compliance and Self-Concept}

In the area of child self-concept, a fairly consistent relationship emerged between children who displayed a higher degree of compliance and those children who indicated adhering to a style of behavior demonstrating self-control. The Self-Control dimension of Eder's self-concept measure includes a low degree of aggressiveness (Aggression), a low reactivity to stress (Stress Reaction), a greater avoidance of scary or potentially harmful situations (Harm-Avoidance) and a higher degree of conformity to rules (Traditionalism). The Traditionalism subscale also includes the item "I am a good girl/boy." The association between this dimension and demonstrated child compliance is a logical one based on the behavioral nature of both and the suggestion that these 
children are aware of and careful to do the right thing for themselves and others. This association similarly corresponds with self-concept development for five-year-olds where children of this age are theorized to make characterizations of the self based more on behaviors than feelings or judgments concerning self-worth.

Overall, no meaningful associations were found between compliance and the two self-acceptance dimensions of the self-concept scale which are based on the more perceptual qualities of a sense of achievement from hard work, confidence in social relationships and a general sense of well-being. This finding fails to support the hypothesis that compliance as an internalized area of competence might be translated into less tangible, more theoretical preoccupations with the quality of interpersonal relationships or perceived self-happiness. There was one unexpected relationship that emerged between the social closeness sub-scale and child noncompliance. This finding may reinforce the idea that compliance behaviors are less related to children's social relationships and perceptions of their experiences than to their relationships with authority figures and more concrete behaviors.

Associations between child self-concept and parental style followed the anticipated direction, with increased parental physical intrusiveness and assertiveness relating to children perceiving themselves as exhibiting increased aggression. Increased parental supportiveness was similarly associated with children's endorsements of themselves as demonstrating more self-control behaviors, suggesting that parental support does influence the child's internalization of social codes and norms for appropriate behavior. One unexpected relationship that emerged was between the Social Potency sub-scale and measures of increased parental physical assertiveness and 
decreased support. While it seems unlikely that decreased parental supportiveness would simultaneously influence increased child aggression and increased success in children's social relationships, this finding may indicate that children who perceived themselves as exhibiting more aggressive behaviors also perceive themselves as more aggressive in their interactions with peers. Based on an examination of it's individual items (e.g. "I pick the games to play" or "I like to tell my friends what to do") the Social Potency sub-scale appears to more strongly measure assertiveness than social success.

\section{The impact of temperament on the parent/child relationship}

The association between perceived self-control, parental style and demonstrated compliance behaviors suggests an important link between these constructs and the potential influence of components of child temperament. Kochanska (1993, 1995, 1997) has done considerable work in this area, exploring the mediating role of child inhibition and impulsivity on self-regulatory behaviors as well as on the relationship between parental style and child compliance. She has demonstrated, for instance, that while more fearful children will demonstrate compliance based on gentle parental discipline, those children who are less fearful tend to demonstrate compliance based more on their positive relationship with the parent rather than the style of discipline employed. The apparent correspondence between this fearful/anxious temperament and those items on the Harm-Avoidance dimension of the self-concept scale in particular seems to lend support within the present study to the significant mediating influence of temperament on observed compliance.

This theorized correspondence between compliance and temperament again 
highlights the tentative nature of any suppositions about causality when exploring the relationship between parenting style and observed child compliance. Although the mediating role of temperament on this relationship seems well supported, it remains unclear whether the child's temperament directly shapes their behavior by modifying their own cognitive processing of parental socialization messages or whether the child's temperament influences the approach used by the parent. It seems likely that these and other processes are taking place simultaneously given the vast array of mediating variables that may potentially be impacting on the development of conscience and process of internalization in children.

Implications for future research

The present study presents numerous implications for future research on the mediating influence of multiple factors on the development of children's models of self and others. Based on the lack of a demonstrated relationship between age and increased compliance, future research might explore the impact of emerging child autonomy and other developmental trends as they impact on demonstrated compliance. Although the lack of association demonstrated between committed compliance and Kochanska's gentle guidance style of parental control may be a result of insensitivity of the methods and small sample size employed in the present study, future studies might incorporate multiple assessments of parental supportiveness and sensitivity over multiple contexts to more closely explore the validity of this particular measure of parental control. Similarly, more work needs to be done employing Eder's measure of child self-concept in order to establish clearer validity ratings for this measure. Future studies employing 
this measure might also examine the differential relationship between children manifesting compliance and the quality of their perceived and demonstrated relationships with authority figures as opposed to peers.

In the area of temperamental influences on child development, future research might continue to explore the individual components of self-control, such as inhibition and mechanisms of behavioral and emotional regulation, in order to further elucidate how child temperament mediates the processing of parental socialization messages, how it shapes and eventually emerges in the child's sense of self, and how it is inevitably manifested through behavior. With the obvious complexity involved in determining direction of influence between parenting styles and child behavior and the mediating impact of inner states and the outside environment on this relationship, there appears to be endless opportunity and unquestionable necessity for continued research in this area. 


\section{APPENDIX 1}

The first component of the study began at 4 months. The mother and infant were involved in a total of 40 home visits by the experimenter which occurred weekly until 14 months. The mother and child were invited into the laboratory at 6,9 and 12 months and the mother was asked to provide weekly reports of their infant's temperament as well as reports about their own personality and temperament.

At 30 months the mother and child were invited into the laboratory for a two hour play session. This laboratory assessment involved a strange situation (Cassidy \& Marvin, 1989) to assess attachment, a clean-up task, ten items from the smile and laugh procedure (Cicchetti \& Sroufe, 1976), a task assessing empathetic response, a mastery motivation procedure (Messer \& Yarrow, 1983), several segments from the MacArthur Story Stem Battery (Bretherton et al, 1990), maternal and examiner prohibition tasks, a behavioral inhibition task and a problem-solving procedure (Matas, 1978).

At four to five years, the mother and child were invited back to lab for another two hour session. After an initial play period, the mother was brought to another room to complete an adult attachment interview while the child participated in a Peabody Picture Vocabulary Test, a puppet interview to asses self-concept (Eder, 1990), the Social Problem-Solving Test (Rubin, 1983) and the Pictorial Scale of Perceived Competence and Social Acceptance of Young Children (Harter and Pike, 1984). 


\section{APPENDIX 2}

\section{TABLE 1}

\section{CHILD COMPLIANCE AT $2 \frac{1}{2}$ AND 5 YEARS OF AGE}

$\begin{array}{cccccc}\text { Committed } & \begin{array}{c}\text { Situational } \\ \text { Compliance }\end{array} & \begin{array}{c}\text { Combined } \\ \text { Compliance }\end{array} & \begin{array}{c}\text { Passive- } \\ \text { Compliance }\end{array} & \begin{array}{c}\text { Overt-Non } \\ \text { Compliance }\end{array} & \begin{array}{c}\text { Defiance } \\ \text { (5 year) }\end{array} \\ \begin{array}{c}\text { (5 year) } \\ \text { (5 year) }\end{array} & \text { (5 year) } & \begin{array}{c}\text { Compliance } \\ \text { (5 year) }\end{array} & \end{array}$

21/2 YEAR

Committed $-.383 *$

Compliance

Situational

Compliance

Combined

$.344 *$ $-.447 * *$

Compliance

Passive-Non

$.329 *$

Compliance

Overt-Non

Compliance

Defiance

$* \mathrm{p}<.05 \quad{ }^{* *} \mathrm{p}<.01$ 


\section{TABLE 2}

CHILD COMPLIANCE AND PARENTAL STYLE

$\begin{array}{ccccc}\text { Committed } & \text { Situational } & \text { Passive Non- } & \begin{array}{c}\text { Overt-Non } \\ \text { Compliance }\end{array} & \text { Compliance } \\ \text { Compliance } & \text { Compliance } & \end{array}$

Gentle Style

$-.327 *$

Forceful

$-.305 *$

$.433 * *$

Style

Quality of

$.403^{* *}$

Assistance

$.533 * *$

$.360 *$

$-.537 * *$

$-.368^{*}$

Supportive Presence

$.481 * *$

$-. .313^{*}$

$-.487^{* *}$

(Clean-Up)

Supportive Presence

(Problem-Solving)

Positive Evaluation

$.467 * *$

$-.406 * *$

Gentle Physical

$.423 * *$

$.383 * *$

Control

Level of

$-.480 * *$

$.479 * *$

$-.412^{* *}$

$.321 *$

$* \mathrm{p}<.05$

$* * \mathrm{p}<.01$

Italicized scores are for five year assessments. 
TABLE 3

CHILD COMPLIANCE AND CHILD SELF-CONCEPT

\begin{tabular}{|c|c|c|c|c|}
\hline $\begin{array}{l}\text { Committed } \\
\text { Compliance }\end{array}$ & $\begin{array}{l}\text { Situational } \\
\text { Compliance }\end{array}$ & $\begin{array}{l}\text { Combined } \\
\text { Compliance }\end{array}$ & $\begin{array}{c}\text { Passive } \\
\text { Non- } \\
\text { Compliance }\end{array}$ & $\begin{array}{l}\text { Overt Non- } \\
\text { Compliance }\end{array}$ \\
\hline
\end{tabular}

Aggression -.318*

Harm-

.397*

$-.367^{*}-. .326^{*}$

Avoidance

Social Closeness

$-.510^{* *}$

$.362 *$
Traditionalism $\quad .339 * \quad-.327 *$
$-.337 *$
$* \mathrm{p}<.05 \quad * * \mathrm{p}<.01$

Italicized scores are for five year assessments. 
TABLE 4

\title{
PARENTAL STYLE AND CHILD SELF-CONCEPT
}

\author{
Aggression Harm-Avoidance Traditionalism Social Potency
}

Quality Assistance

$.462 * *$

(Clean-Up)

Quality Assistance

$-. .408 *$

(Problem-Solving)

Distal Physical Control

$.342 *$

$.372 *$

Assertive Physical

Control

$.399 * *$

.345 *

Level of Involvement

$-.320 *$

$-.352 *$

$* \mathrm{p}<.05^{* *} \mathrm{p}<.01$

Italicized scores are for five year assessments. 


\title{
Clean-Up Task Coding Manual Providence Family Study Version 1.0 (April 1998)
}

Laura Giusti

Elena Mirsky

Susan Dickstein

Ronald Seifer

\author{
Adapted From \\ Child Compliance/Mother Discipline Project Coding/Entry Manual \\ Grazyna Kochanska \\ Terri L. Tjebkes \\ University of Iowa
}

Requests for manuals or further information may be directed to the Providence Family Study, Ronald Seifer, Principal Investigator, Brown University, Bradley Hospital, 1011 Veterans Memorial Parkway, East Providence, RI 02915. E-mail to Ronald_Seifer@brown.edu 


\section{Clean-Up Task Coding Manual}

This is the first of two manuals (Clean-Up Task and Prohibitions) used in the assessment of maternal control styles and child compliance in the context of the development of internalization and child conscience. The coding systems were designed for use in contexts that are saturated with control issues typical for early childhood.

In the Clean-Up Task coding manual, child behavior is coded using categories of compliance in response to a maternal directive to clean-up toys. Maternal control is rated on global styles of discipline, as well as more specific behaviors regarding maternal physical intervention with the child. Maternal use of positive or negative evaluations, as well as the overall quality and level of her involvement are recorded.

\section{Timing of Segments}

For the Clean-Up Task coding system, coding intervals correspond with time segments from the PFS Affect Coding system -two 15-second segments are used for each of the 30-second Affect Coding segments. To capture the instructions provided by the examiner, coding should begin with the 15 -second segment immediately prior to the beginning of the Affect coding for the clean-up task indicated on existing Affect Coding sheets (see definition below). For example, if Affect coding for the clean-up task begins at $23 \mathrm{~m}: 45 \mathrm{~s}$, Clean-up coding should begin at $23 \mathrm{~m}: 30 \mathrm{~s}$. [Note that all times in this manual refer to the minutes and seconds of the time of day clock superimposed on the video record. These are abbreviated with $\underline{\underline{m}}$ indicating minutes and $\underline{s}$ indicating seconds.]

If Affect coding has not yet been completed, the coder will need to determine the starting point for the clean-up task for the Affect coding, prior to determining the starting point the coding for Clean-Up. The timing for the Affect clean-up task is designated to begin at the moment the experimenter closes the door to leave following administration of the direction to clean-up. For example, if the experimenter gave the instruction to the mother to clean, and left the room closing the door at $12 \mathrm{~m}: 24 \mathrm{~s}$, $12 \mathrm{~m}: 24 \mathrm{~s}$ would be the starting point for the Affect coding clean-up task, and $12 \mathrm{~m}: 09 \mathrm{~s}$ (15 seconds prior) would be the starting point for the Compliance coding.

If in the initial segment there are less than 5 seconds following the administration of the examiner's instruction to clean, the segment will be coded 9 to indicate insufficient data. Coding should continue in 15 second segments from that point forward until the experimenter has re-entered the room to signal the end of the clean-up, or until the mother signals the end of the clean-up.

The end of coding results when the mother indicates that the clean-up is complete (verbally or non-verbally), or when the experimenter enters the room. If there are less than five seconds in the segment in which this occurs, the segment will be coded 9 to indicate insufficient data.

For each segment, assign the following: 
- one predominant code for Child Compliance;

- one predominant code for Mother Discipline-Global Style

- a presence/absence code for four Physical Control of Child behaviors

- one predominant code of any maternal Negative evaluations

- one predominant code of any maternal Positive evaluations

- a presence/absence code for maternal changes of agenda

For the entire session, assign global codes for:

- Level of Mother Involvement

- Quality of Mother Assistance

- Mother Supportive Presence.

Ideally, and in nearly all cases, codes should be assigned independent of previous or subsequent codes; that is, coders should be able to achieve reliability for segments which are scored in isolation. However, there may be some instances in which the coder feels that the broader context (i.e., mother or child's behavior in previous or subsequent segment) significantly influences the interpretation and rating of "borderline" or hard-to-score behaviors. Only in these cases is it appropriate to take into consideration the context of the interaction/behavior outside of the 15 second segment. 


\section{Clean-Up Task Coding System}

\section{Experimenter Directions}

Prior to coding the mother-child interaction, the manner in which the experimenter presented the directions for the clean-up task are rated using the following codes:

1 Standard direction

2. The experimenter clearly indicates that she wants the mother to have the child clean the toys. "Mom, please have Jane clean the toys now."

3. Maternal direction

The experimenter gives a direction that suggests she wants the mother to clean the toys. "Mom, if you could please clean the toys."

4- Ambiguous direction

The experimenter gives a direction that is difficult to determine who is being requested to clean the toys. "It's time to clean-up now."

5. Other direction

The experimenter gives a direction that does not fit the above categories. Coder should fill in the type of instruction provided by the examiner.

6. Can't determine

The experimenter gave the direction off-screen or for some reason could not be heard on the tape.

In addition, any incentive that the experimenter offered to the mother/child for cleaning the toys should be noted. Any incentive that the mother may offer is not to be recorded here.

Standard, non-incentive statements:

"I'll be back when you're done."

"When you're done, I'll come back with the next activity/more stuff."

Incentive statements:

"When you're done cleaning these toys, I'll bring you other toys."

“As soon as you're done I'll bring you something else fun to do." 


\section{Child Compliance}

Each 15 second time-segment is assigned one Child Compliance code. When assigning these codes, the standard rule is to assign the child compliance code that corresponds with the behavior that is most predominant during that segment. That is, if the child displays behavior indicative of two Compliance codes (e.g., Situational Compliance and Passive Noncompliance), code whichever was the most predominant (i.e., occurred for the longest portion of the segment) during the segment. Exceptions to the standard rule of predominance are the presence of any Overt Resistance or Overt Defiance behaviors (codes $5 \& 6$ described below, with 6 taking precedence over 5). For example, if the child is demonstrating Passive Noncompliance for the majority of the segment, but demonstrates any Overt Resistance behavior during the same segment, Overt Resistance would take precedence over the predominant Passive Noncompliance for that segment. These decision rules are hereafter referred to as the predominance rule (child codes 14), and the presence rule (child codes 5-6). The end of the clean-up is signaled when the mother verbally or non-verbally indicates that the task is complete, or when the experimenter enters the room. If there are less than five seconds in the segment in which the end of the clean-up occurs, do not code that segment.

1. Time Out

2. Committed Compliance

3. Situational Compliance

4- Passive Noncompliance

5• Overt Resistance *

6. Overt Defiance *

* These codes, when present, take precedence over the predominance of other codes, with 6 taking precedence over 5

Definitions of codes follow below. 


\section{Child Compliance (continued)}

\section{Time Out}

There is no on-task clean-up behavior by the child, and the mother has explicitly suspended the expectation that the child should be cleaning up.

Must meet following criteria to be coded 1 :

- The child is not cleaning up.

- There is a total absence of maternal directives to clean-up.

The coder should also feel confident that:

- The mother has explicitly suspended (verbally or non-verbally) her expectation that the child should be cleaning up.

A Time-Out code is not appropriate simply because the mother is not giving explicit directives to clean during a segment in which her child is not cleaning. In other words, unless the coder feels confident that the mother has suspended the expectation that the child should be cleaning (see examples 3 and 4 below), the child's compliance should be interpreted in the context of the previously stated expectation that $\mathrm{s} / \mathrm{he}$ should be cleaning. For example, if a child is looking at toys instead of cleaning, and the mother comments, "You really like that fire engine," this would not be sufficient to suggest that the agenda to clean-up had changed, and a code of Passive Noncompliance would be more appropriate.

NOTE: When coding Time-Out, the physical intervention code for the corresponding segment should be 0 (No Physical Control) .

\section{Examples:}

Mother is unaware of the off-task behavior. Mother is attending to her own unrelated agenda, has forgotten the task, or does not notice child's off-task behavior (e.g., she is engrossed in magazine) or she could care less about, or is actively resistant to, the clean-up task (e.g., "We'll clean-up later").

Mother is trying to prevent child from "undoing" completed clean-up task. Mother engages child in play, picks up, or otherwise distracts child to prevent him/her from removing toys from basket once they are all put away. (This should signal the end of coding).

Mother becomes interested in an unrelated task. An exchange that may have started out as an indirect route to get the child to clean up may change into an educational task (e.g., mother is showing child an object and trying to teach him/her the name of it).

Mother uses time-out to smooth uncooperative behavior. She anticipates child's 
patience/cooperation with the clean-up is waning and attempts to avoid child defiance by explicitly introducing a break or distracting the child from the task. (e.g., "Before we put this away, lets look at it for a minute," or "Should we look out the window and see if we can find any birds?"). 


\section{Child Compliance (continued)}

\section{Committed Compliance}

Wholehearted embrace of maternal agenda.

Must meet the following criteria to be coded 2:

- The child is actively involved in picking up the toys.

- The child's affect is positive or neutral with regard to picking up toys.

The coder should also feel confident that:

- The child's attention does not waver for most of the segment.

- The child would continue to clean-up even if mother stopped offering prompts/praise.

With 12-15 month olds, it is often unrealistic to expect that they will keep up the task without mother's involvement. Committed Compliance may be coded even if the mother continues to be engaged with the child (e.g., clap, sing, or praise) to support his/her progress.

If the child's attention wavers, the origin and purpose of the distraction must be evaluated:

- If the child's attention briefly wavers due to maternal distraction (e.g., mother's question, request, comment), the child should still receive a Code 2 (a Time-Out code may be more appropriate if mother has explicitly suspended the clean-up task).

- If the distraction was spontaneous (e.g., child counting the toys, commenting on colors), but does not significantly interrupt the flow of the clean-up, Code 2 is also appropriate.

- If, however, the child becomes spontaneously distracted and he/she ceases or significantly interrupts the flow of clean-up, a Code 3 or 4 would be more appropriate.

\section{Examples:}

Child eagerly snatches toys from mom and throws them in basket.

Child claps, smiles, or otherwise demonstrates positive affect as s/he puts toys in basket.

Child picks up toys the mother did not pick up and puts in basket. 


\section{Child Compliance (continued)}

\section{Situational Compliance}

Receptive to maternal agenda, but half-hearted cooperation, only responsive to immediate maternal directives.

Must meet the following criteria to be coded 3:

- The child is picking up toys.

- The mother gives reminders, prompts, directions, or otherwise non-verbally encourages child to continue the clean-up task.

- There is no evidence of verbal or physical overt resistance regarding the cleanup task.

The coder should also feel confident that:

- The child is generally willing/trying to comply even though $\mathrm{s} / \mathrm{he}$ might want to be doing something else.

- Without prompting, the child would be unlikely to continue the clean-up.

\section{Examples:}

Distractions and slippage are common. While carrying toy to basket, child begins to play with it, or becomes distracted by something outside window.

NOTE: To differentiate between spontaneous distraction (consistent with code 3 ) and "stalling" (consistent with code 4), consider to what degree the child complied by putting any toys away during that segment (suggests 3), and whether the distraction feels more purposeful (suggests 4).

Mothers may attempt to turn the clean-up into a game in order to elicit cooperation. "Let's make baskets!" or "Who can do it faster?" [NOTE: If the child then becomes cooperative, but does not demonstrate particular joy or enthusiasm about the game (i.e., the clean-up is still not her genuine agenda), a Code 3 is most appropriate. If the child becomes joyful and enthusiastic about the clean-up game (i.e., the clean-up becomes her genuine agenda), then a Code of 2 may be more appropriate.]

Child is cleaning only because mother is cleaning. If the child is handing toys to mom, or receiving toys from her to be thrown in basket, and mother slows down or stops, the child stops, too.

To discriminate between a genuine, temporary distraction from the clean-up (Code 3), versus "stalling" (Code 4), consider: a) does the child put any toys away during the segment (i.e. is there any compliance?), and b) do the distractions seem purposeful or 
intentional? If there is no compliance during the segment, and/or the distractions seem purposeful, a code of 4 is more appropriate. 


\section{Child Compliance (continued)}

\section{Passive Noncompliance}

Passively reluctant to accept maternal agenda, non-cooperative, or ignoring directives without anger.

Must meet the following criteria to be coded 4 :

- There are few to no toys picked up by child.

- The child does not pick up toys unless prompted.

- The child is not demonstrating anger or overt verbal or physical resistance (Code $6)$.

The coder should also feel confident that:

- When prompted to clean, child is most likely resistant and reluctant to comply.

- The child does not want to make the conflict explicit, is not seeking a power struggle with mother, and is not drawing attention to his/her noncompliance (i.e. $\mathrm{He}$ is trying to get away with it).

\section{Examples:}

When prompted by mother, the child ignores the prompts. The child may pretend not to hear the mother, continue to play in silence, or talk to self.

The child tries to distract the mother from the clean-up. The child may try to start a conversation that is unrelated to the task, try to engage the mother in play, ask for a snack, or otherwise try to "stall" the clean-up.

The child does not demonstrate defiance or try to engage mother in a power struggle. The child may ignore mother's directions to put a toy in the basket, but does not purposefully pick it up and put it elsewhere, which might suggest an intention to "spite" mother.

Child is not cleaning and the mother is waiting quietly. The mother may have given an initial prompt and is waiting quietly for the child to comply. The initial agenda remains unchanged (i.e., she still wants child to clean) but there is a break in giving explicit directions.

NOTE: In 12-15-month-olds, getting the toys out of the basket and trying to leave the room are also coded as Passive Noncompliance (unless accompanied by more overt resistance or anger). 


\section{Child Compliance (continued)}

\section{Overt Resistance*}

Overtly refusing or negotiating maternal agenda without clearly articulated anger or defiance.

Must meet the following criteria:

- There are few to no toys picked up by child and the child does not pick up toys unless prompted.

- The child is not demonstrating anger or aversive protest (Code 6).

- The child overtly refuses to clean-up, or negotiates to avoid clean-up

The coder should also feel confident that:

- When prompted to clean, child is most likely resistant or tries to negotiate.

- The child wants to make the conflict explicit, engage in power struggle, or draw attention to his/her non-compliance.

\section{Examples:}

The child overtly refuses to clean-up via verbal means: "I don't want to clean-up" or "No."

The child overtly refuses to clean-up via non-verbal means. The child orients away from the task (e.g., climbs into tunnel) or the mother (turns back to her) to avoid task. The child may also put toys away differently than mother has directed (not putting people in the airplane as directed by mother).

The child tries to negotiate to avoid cleaning. "Let's play cars first," or "I'm too tired," or "Just a few more minutes," or "It's not my job to clean," or "I can't."

If there is a clear demonstration of anger, code 6 would be more appropriate. However, code 5 can be used when there is a display of minor frustration, which is indicated by a brief or poorly articulated display of anger, frustration, or affectively aversive body expression. Examples of "minor frustration" include a brief grumble, mild pound of fist, brief shake of head with frown, etc. If there is a demonstration of more than minor frustration in the overall context of overt resistance, code 6 is more appropriate.

* NOTE: Overt Resistance rarely lasts throughout most of the segment (and therefore, would yield extremely low rates of occurrence using the predominance rule).

Therefore, if at any time during the segment

1 - an overt oppositional response is clearly present, or 
2• oppositional-type responses happen more than once in a segment, and

3. there is no substantial compliance,

the segment should be coded as 5 even if it was not the predominant behavior for the segment. The only exception is if any Overt Defiance (code 6) is observed, in which case a code 6 should be assigned. 


\section{Child Compliance (continued)}

\section{Overt Defiance*}

Overtly defying/rejecting/protesting maternal agenda with accompanying anger or defiance.

Must meet the following criteria:

- There are few to no toys picked up by child.

- The child does not pick up toys unless prompted.

- The child overtly refuses, protests or otherwise resists cleaning-up, with verbal or physical expression of anger or defiance.

The coder should also feel confident that:

- The child is not trying to negotiate with the mother, but is actively engaging in a power struggle or defying her.

\section{Examples:}

The child overtly refuses to clean-up, and expresses anger verbally. "I don't want to clean-up!" or "No!"

The child expresses substantial frustration (i.e., more than minor frustration as described in code 5) or anger non-verbally. The child may begin crying, whining loudly, throwing a temper tantrum, or being aggressive with toys or mother.

The child is overtly defiant or engages in power struggle with mother. The child may defy mother's directions by covering his ears or sticking out his tongue, or by doing the opposite of what she asks (e.g., mother says, "Hand me the toy," and child purposefully puts toy out of her reach).

* NOTE: Defiance rarely lasts throughout most of the segment (and therefore, would yield extremely low rates of occurrence using the predominance rule).

Therefore, if at any time during the segment

1. an overt oppositional response with anger is clearly present, or

2- other expressions of minor frustration happen more than once in a segment, and

3. there is no substantial compliance,

the segment should be coded as 6 . 


\section{Maternal Discipline: Global Control}

Maternal Global Control codes refer to the general style of influence that the mother uses in order to elicit child compliance. The codes are designed to assess the degree of power or coercion that the mother employs versus other induction techniques (e.g., reasoning, encouraging, praising).

Each 15 second time-segment is assigned one Maternal Global Control code. As with the Child Compliance codes, when assigning Maternal Global Control codes, the standard rule is to assign the code that is most predominant during that segment. That is, if the mother displays behavior indicative of two codes (e.g., Gentle Guidance and Social Exchange), code whichever was the most predominant (i.e., occurred for the longest portion of the segment) during the segment. The exception to the standard rule of predominance occurs in the presence of Forceful, Negative, High-Powered Control behaviors (code 4; see explanations below).

0 . No interaction

1. Social Exchange

2. Gentle Guidance

3. Control

4. Forceful, Negative, High-power Control *

* This code, when present, take precedence over the predominance of other codes

Definitions of codes follow below. 


\section{Maternal Discipline: Global Control (continued)}

\section{No interaction}

No verbal or physical overture of interaction by mother; she is psychologically uninvolved with child.

Must meet the following criteria to be coded 0:

- The mother does not talk to the child.

- The mother is not otherwise attending to the child.

The coder should also feel confident that:

- The mother is psychologically uninvolved with the child.

\section{Examples:}

Mother is engaged in her own agenda. She is reading a magazine, working on questionnaires, or looking out the window.

Mother is engaged in thought. She may be looking toward child, but appears unaware of him/her, and is not demonstrating any awareness of the child's behavior.

Note: Do not use Code 0 simply on the basis of the mother not speaking to the child during the segment. Although it is necessary for the mother not to speak to the child to earn a Code 0 , it is not sufficient to earn the code if she is otherwise psychologically engaged with the child.

\section{Examples of Non- 0 codes:}

The mother is offering a quiet, "supportive presence." The mother may be watching the child clean-up, offering psychological support simply by her presence (code 2 more appropriate).

The mother is being quietly threatening. The mother may be watching the child to see if s/he will follow through with the instructions, and with body language (e.g., negative affect, threatening body posture) communicating her monitoring of child's behavior (code 3 or 4 more appropriate). 


\section{Maternal Discipline: Global Control (continued)}

\section{Social Exchange}

Mother interacts with child unrelated to the clean-up task, and without attempt to control the child's behavior regarding the clean-up.

Must meet the following criteria to be coded 1:

- The mother and child are engaged in some type of interaction.

- There is no reference made to the clean-up task.

\section{Examples:}

Mother and child are engaged in off-task conversation. They may be talking about things unrelated to the lab, or even talking about objects in the room as long as it does not pertain to the clean-up task (see NOTE).

Mother is engaged in teaching task with child. The mother may be pointing out/teaching child about shapes, colors, etc. of different objects, even the clean-up toys, in the room (see NOTE).

Mother and child are playing with one of the toys. The mother may have initiated or given permission to play with a toy as a break from the clean-up task (see NOTE).

NOTE: The assignment of the Social Exchange code 1 typically corresponds with Child Compliance code 1 (Time Out) if the mother initiated or permitted the social exchange through an explicit change in agenda (i.e., mother has suspended the expectation that child should be cleaning). The presence or absence of any mother initiated, explicit changes in the agenda will also be recorded for each segment as explained below. However, if the child initiated the social exchange as a way to stall or avoid cleaning the toys (Child Compliance code 4, Passive Noncompliance), and the mother has not given indication that she has suspended the original expectation that the child should be cleaning up, a code of 2 , Gentle Guidance, is more appropriate. 


\section{Maternal Discipline: Global Control (continued)}

\section{Gentle Guidance}

Mother directs child behavior in clean-up task gently, subtly, or playfully.

Must meet the following criteria:

- Mother is trying to encourage child to clean-up.

- Mother's affect is positive.

The coder should also feel confident that:

- Mother is trying to encourage child to want to clean-up.

- Mother wants to make the task enjoyable for the child.

\section{Examples:}

Mother tries to get child to clean-up using gentle, polite suggestions. She may gently suggest, "The nice lady would like us to clean-up; how about we do it together?" or "We know how to clean-up! Why don't you show her what a great job you can do?"

Any directions mother offers are veiled in positive affect or playful tone. She might say, "Okay! It's time to clean-up!" with positive, excited affect, or in a joking manner, "I thought the lady said YOU were supposed to clean-up, not me!" with positive affect, and maybe a tickle.

Mother turns the clean-up into a game. She may sing or clap to make the task fun. She may playfully toss toys into the basket and ask, "Can you do this?" She may offer to hold the basket to let the child throw the toys in.

Mother offers positive feedback or incentives for clean-up. She may praise the child (e.g., "What a good helper you are!" or "Great job cleaning!"), or offer rewards (e.g., "You are doing such a nice job, I think we'll get a snack after you're done!").

Mother is providing "supportive presence" as child cleans. She may be watching the child clean, without verbally interacting with child, but demonstrating that she is psychologically involved and lending quiet, emotional support to the child's compliant behavior by smiling or other non-verbals.

Mother engages in brief social exchange to bridge gaps in giving directions. She may be trying to avoid being too controlling by making social comments between directions (e.g., "You really like that fire engine"; "What a pretty doll."). 


\section{Maternal Discipline: Global Control (continued)}

\section{Control}

Directing behavior regarding clean-up task in direct, no-nonsense, matter-of-fact, but non-forceful manner.

Must meet the following criteria to be coded 3:

- Mother is trying to encourage child to clean-up.

- Mother uses explicit directions or commands, or indirect commands.

- Mother is not displaying forceful tone of voice, overt anger or threats (Code 4).

- Mother is watching the child put away toys and is quietly expectant.

The coder should also feel confident that:

- Mother is not actively trying to foster the child's desire to comply.

- Mother is more likely to be overriding the child's agenda, pace, or other behavior.

\section{Examples:}

Mother gives directions to clean-up. She may say in a matter of fact tone, "It is time to clean-up now," or "Please follow directions."

Mother uses prohibitions. She may say, "Please do not play now," or "No no."

Mother offers reasons for cleaning-up. She may explain, "We have to put them all away," or "Because the lady told you to do it," or "Because it's not nice to leave toys out."

Mother directs child how to clean-up. She may give step-by-step directions about which toys to pick up ("Start with that one," or "Let's get that one next," or "Pick up the doll, too," or "You forgot the train,").

Mother may be "wishy-washy" or ineffective in her attempt to give directions. She may ask, "You don't want to play with this one, right? So why don't we put it in here?"; "Don't you want to help me? I need your help."

The mother is being quietly controlling. The mother may be watching the child to see if s/he will follow through with the instructions, and with body language (e.g., proximity, vigilance) communicating her monitoring of child's behavior.

NOTE: In situations where the experimenter does not present the directions in the 
standard form, a code 3 may be used as a default code for mothers who are not actively engaged with the child in the clean-up process. However, if the mother is obviously engaged in another activity, such as reading a magazine or looking out the window, then a code of 0 (No Interaction) is more appropriate. 


\section{Maternal Discipline: Global Control (continued)}

\section{Forceful, Negative, High-power Control*}

Directing behavior regarding clean-up task in a somewhat forceful or power-assertive manner using raised voice, decisive tone, threats, or negatives, and involving a clash of wills or power struggle.

Must meet the following criteria to be coded 4:

- Mother is directing child to clean-up using directions, commands, or prohibitions.

- Mother is displaying forceful or stern tone of voice, overt anger, or threats.

The coder should also feel confident that:

- There is a clash of wills or power struggle between mother and child.

In addition, any explicit put-down or negative evaluation of the child (not of his/her behavior only), earns an automatic code of 4 for that segment. (A negative evaluation of the child's behavior may or may not earn a code of 4 depending on the other factors in the segment.)

\section{Examples:}

Mother gives demands or prohibitions to clean-up in stern, angry or threatening manner. In stern, angry, or threatening tone she may direct, "I said, it is time to clean-up!" or "Please follow my directions, now!" or "Start with the train!" or prohibit, "I said no!" or "Stop that!" or "This is not the way we clean!"

Mother uses direct or implied threats. "If you don't stop playing now you won't get to play later," or "It's too bad for you that you haven't cleaned up!" or "You better start listening!" or "I'm setting my watch...".

Mother offers reasons for cleaning-up. She may explain in angry tone, "You have to put them all away," or "Because I said so!" or "Because it's rude to leave toys out!"

The mother is being quietly threatening. The mother may be watching the child to see if s/he will follow through with the instructions, and with body language (e.g., negative affect, threatening body posture) communicating her threatening monitoring of child's behavior.

* NOTE: Forceful, negative, or high-power control rarely lasts throughout most of the segment (and therefore, would yield extremely low rates of occurrence using the predominance rule). Therefore, if at any time during the segment

a) overt anger or threats are clearly present, or 
b) impatient, low-level anger is evident more than once in a segment,

the segment should be coded as 4 . If, however, there is a single demonstration of minor frustration during a segment, as indicated by a brief and poorly articulated behavior (e.g., shakes head in frustration; 'C'mon honey, I don't want to get angry"), code 3 is more appropriate. 


\section{Maternal Discipline: Physical Control of Child}

This set of four scales indicate the presence or absence of Physical Control of Child behaviors by the mother that occur in each 15 -second time segments. It is possible that a mother could demonstrate all or none of the four behaviors.

These codes are meant to capture the physical movements and gestures that are made by the mother in relation to the child and the clean-up task. Do not code physical control of child during interactions unrelated to the clean-up (i.e. during "time-out," "social exchange," or "no interaction" codes). For this set of codes, maternal verbalizations and affect are relevant only when they accompany and are used to interpret physical contact with the child. Each of the following is coded as to whether it is present or absent in the 15-second interval.

1 Distal Physical Signal

2- Gentle Physical Control/guidance

3- Assertive Physical Control

4- Forceful, Negative, High-power Control 


\section{Maternal Discipline: Physical Control of Child (continued)}

\section{Distal Physical Signal}

Mother makes distal gestures to direct the clean-up of toys without physical contact with child.

Must meet following criteria to be coded as occurring:

- Mother makes physical gesture or movement regarding the clean-up.

- Mother does not touch the child.

The coder should also feel confident that:

- The gesture is made to enlist child's compliance to clean-up.

\section{Examples:}

Mother manipulates materials to assist child's participation in clean-up. She may move basket closer to the child, hold it for the child as the child puts toys in, organize toys in basket to fit better, or place toys closer to child.

Mother models clean-up to encourage child's participation. She may show child how to put a toy in the basket.

Mother makes gestures without actually manipulating materials. She may point to toys to pick up, or to the basket, or nod in the direction of the toys to indicate where child is to put them.

NOTE: Do not code Distal Physical Signal if the mother is using physical gestures to complete the clean-up herself, rather than encouraging the child to do it. If the mother moves basket closer to herself, puts toys away when child is not watching, and does not appear to care whether or not the child has noticed, this would warrant no presence of a Physical Control of Child code, and a code of 2 or higher on the overall rating of Maternal Level of Involvement. 
Maternal Discipline: Physical Control of Child (continued)

Gentle Physical Control/Guidance

There is physical contact with the child in gentle, non-forceful manner.

Must meet the following criteria to be coded as occurring:

- The mother makes physical contact with child regarding clean-up.

The coder should also feel confident that:

- Mother is utilizing physical contact to encourage child to want to clean up.

- Mother's gesture is not due to clash of wills or power struggle.

\section{Examples:}

Mother uses gentle physical contact to get child's attention. She may tap child on shoulder or hold child's face gently to give or remind her of direction.

Mother tries to get child to clean-up using gentle guidance. She may gently turn child toward basket, hold her hand to walk her away from the door, or put a toy in the child's hand.

Mother gently hands child toys. She may pick up toys and hand to child to put in basket.

Mother uses touch mediated by another object to enlist child's compliance. She may use puppet to touch child to encourage clean-up. 


\section{Maternal Discipline: Physical Control of Child (continued)}

\section{Assertive Physical Control}

Mother uses firm or decisive contact with child without physical demonstration of anger (i.e., rough physical control).

Must meet the following criteria to be coded as occurring:

- Mother makes firm physical contact with child to get child to clean-up.

- Mother is not displaying overt physical anger.

The coder should also feel confident that:

- The physical gesture is evidence of, or instigates, a clash of wills or power struggle between mother and child.

\section{Examples:}

Mother uses firm physical contact to get child's attention. She may turn child decisively toward her, or hold child's face firmly to give or remind her of direction.

Mother tries to get child to clean-up using firm guidance. She may decisively turn child toward basket, firmly hold her hand to walk her away from the door, plant her foot to block child's movement away from task, or decisively put a toy in the child's hand.

NOTE: Mother's angry, threatening verbalizations are not sufficient, nor necessary, to receive a Physical Control code of Assertive or Forceful Control. It is the quality of the physical contact that is the specific focus of this code. 


\section{Maternal Discipline: Physical Control of Child (continued)}

\section{Forceful, Negative, High-Power Control}

Mother uses firm, decisive, or forceful contact with child (i.e., rough physical control) with accompanying demonstration of anger.

Must meet the following criteria to be coded as occurring:

- Mother makes firm physical contact with child to get child to clean-up.

- Mother is displaying overt physical anger or intent to hurt or frighten child.

\section{Examples:}

Mother uses forceful physical control to get child's attention. She may grab child's arm, shake child, or otherwise handle roughly to get child's attention or remind her of clean-up task.

Mother tries to get child to clean-up using force. She may yank toys abruptly from child's hand, or pick her up roughly and move her to basket.

Mother uses physical discipline to punish child. She may spank, slap, pinch, etc. to punish child's noncompliance or oppositionality. 


\section{Maternal Change of Agenda}

This code is used to indicate presence or absence of something other than the clean-up task at hand in the mother's expectations regarding the child's behavior. This is useful for marking distinctions among the codes for Mother Discipline-Global Control.

\section{Change of Agenda}

Mother initiates an explicit change in agenda from the clean-up task to a social exchange.

Must meet the following criteria to be considered a change in agenda:

- The mother initiated the change in agenda.

- The change in agenda is explicit.

The coder must also feel confident that:

- The mother is not still waiting for the child to comply.

\section{Examples:}

Mother explicitly initiated playing with one of the toys as a break. (e.g.,"Let's take a break and play before we finish cleaning-up"). This would also include instances in which the mother nonverbally engages the child in an off-task activity such as by getting down on the floor and playing with the toys.

The mother may give the child a competing direction. She may interrupt her directions regarding the clean-up to give the child an unrelated direction (e.g., "Push the peg through - use the hammer"; "Come here- let me wipe your nose").

The presence of change in agenda should be indicated for each segment that the mother has explicitly initiated an agenda other than the clean-up; consequently, she has suspended the agenda that the child should be cleaning. There is no need, however, to continue marking change of agenda for consecutive segments after the initial change was made unless a new agenda is explicitly stated.

NOTE: When a change of agenda occurs and codes of "time-out" and "social exchange"/"no interaction" are given (indicating no clean-up task behavior during that segment), do not code any child compliance or mother discipline- physical control codes for that segment. However, if the change of agenda occurs at the end of the segment, the segment should still be coded for the majority of observed child compliance and mother discipline and a change of codes will most likely be appropriate for the following segment. 


\section{Maternal Evaluations of Child}

The occurrence of maternal Positive or Negative Evaluative/Responsive statements or non-verbal behaviors regarding the child and/or the child's behavior is recorded. For each time segment, indicate if Positive or Negative Evaluations/Responses were made, and if so, whether they were Task-Specific or General in nature. For those cases in which it is difficult to determine whether the mother's comment or non-verbal response is specific to the clean-up, or more general in nature, the general code should be used. When both are clearly present, precedence should be given to statements specific to the clean-up task.

The codes for positive and negative evaluative statements are

0 . No evaluative statement/response

1. Clean-up task specific

2. General evaluation (not related to clean-up task) 
Maternal Evaluations of Child: Positive Evaluation or Response (continued)

\section{Clean-up Task-Specific Positive Evaluation}

Positive appraisal of child's progress/behavior related to clean-up

Must meet the following criteria to be coded as Task-Specific Positive Evaluation:

- Mother is evaluating or responding to child's behavior specifically regarding clean-up with verbal or non-verbal communication.

- Mother's evaluation or response is positive.

\section{Examples:}

"You're doing a great job cleaning."

"I like how you're being so careful with the toys."

"Wow!"

"Thank you."

"You're such a good boy!" (referring to his cleaning-up)

Mother claps, hugs, or otherwise non-verbally communicates her approval of child's clean-up behavior. 
Maternal Evaluations of Child: Positive Evaluation or Response (continued)

2. Global Positive Evaluation (not related to clean-up task)

Positive appraisal of child unrelated to clean-up

Must meet the following criteria to be coded as Global/General Positive Evaluation:

- Mother is making evaluation or response to child regarding something unrelated to the clean-up task.

- Mother's evaluation or response is positive.

\section{Examples:}

"You look so nice today."

"You're such a good boy." (referring to his behavior in general)

"What a sweetie."

Giving child a hug or kiss 
Maternal Evaluations of Child: Negative Evaluation or Response (continued)

\section{Clean-up Task-Specific Negative Evaluation}

Negative appraisal of child's progress/behavior related to clean-up

Must meet the following criteria to be coded as Task-Specific Negative Evaluation:

- Mother is evaluating or responding to child's behavior regarding clean-up with verbal or non-verbal communication.

- Mother's evaluation or response is negatively critical.

Examples:

"You're not going fast enough."

"You aren't doing it right."

"You don't want to? Boo on you."

Shaking head with frown to communicate disapproval of child's behavior 
Maternal Evaluations of Child: Negative Evaluation or Response (continued)

2. Global Negative Evaluation (not related to clean-up task)

Negative appraisal of child unrelated to clean-up

Must meet the following criteria to be coded as Global/General Negative Evaluation:

- Mother is evaluating or responding to child regarding something unrelated to the clean-up task.

- Mother's evaluation or response is negatively critical.

Examples:

"Your hair looks terrible today."

"You've been bad all week." 


\section{Overall Ratings of Mother Behavior}

In addition to coding of the 15-second time intervals, mothers' overall approach to the control situation is rated. These overall ratings are for entire clean-up task, and should reflect the best aggregate assessment of the maternal control style. The three overall codes assigned are for Quality of Mother Assistance (summarizing the technical aspects of her teaching/control), Supportive Presence (summarizing the emotional climate set by the mother), and Level of Involvement (summarizing the degree to which the mother actually completes the task set for the child). These codes are derived from the teaching style/joint problem solving literature, particularly the work of Sroufe and colleagues. 


\section{Overall Ratings of Mother Behavior (continued)}

\section{Quality of Mother Assistance (Teaching Style)}

This is a global code that is used to determine the degree to which mother assists child in a way that keeps the child interested and motivated in the clean-up task, while allowing him/her maximum opportunity for autonomous behavior. In addition to considering if the pair was successful in the clean-up task, it is also important to consider whether the mother's teaching style provided a positive learning opportunity for the child. Consider the following characteristics of mother's teaching style: timing, pacing, grading, cooperation, space, and control, as well as flexibility, clarity, and effectiveness of instructions. Mothers are given higher scores when they provide a context in which the child can succeed at completing the task, and the mother's teaching style is effective in helping the child learn about completing tasks in general. Lower scores are given when mothers do not give the child a chance to complete the task, do not intervene when the child is not completing the task, over- or underestimate their child's capability, or do not provide assistance that meets the child's needs. A score of 1 should be for those dyads that do not complete the clean-up task. Scores of 1 and 2 should be reserved for those mothers who provide assistance that is disruptive of the child's task completion. Scores of 2 and 3 should be given to those mothers who do not provide for independent task-completion behavior by the child. Scores of 4 and 5 should reflect increasing degrees of mother effectiveness in providing autonomous taskcompletion experiences for the child - preparing the child for when the mother isn't there in the future.

1. Mother is totally intrusive or completely ineffective and may distract or frustrate child, or mother is totally uninvolved. Result is that the child cannot complete the task.

2- Mother contributes little effective assistance and could improve on most of the relevant characteristics of anticipating frustration, timing, pacing, etc. The mother provides little effective organization of the child's behavior and introduces some disorganization of or interference with the child's ability to complete the task independently. Child may or may not eventually be able to complete the task.

3- Mother is minimally competent; she provides sufficient opportunity for the child to complete the task but may not allow the child to do so independently. She may inhibit the child from working independently by telling the child what to do or may simply demonstrate minimal involvement in the task. Overall, the mother fails to provide a context in which the child can feel accomplished. Mother's assistance could improve on several of the relevant characteristics.

4- The mother allows the child to work independently for the most part and creates a context in which the child may feel somewhat accomplished. Some learning is incorporated into completing the task. Mother's assistance is good but could improve on one or two of the relevant characteristics. 
5- Mother provides clear, well-paced, effective assistance. Mother initially orients child to the task, then sits back and allows the child to demonstrate competence by completing it autonomously. Mother offers assistance or effective modeling according to child's needs, and provides several opportunities for the child to learn while completing the task. Mother offers sufficient encouragement and positive feedback so that the child feels accomplished, and remains engaged een though the child is cleaning independently.

6- Child completes clean-up task very quickly without any need of assistance from mother (i.e., no time for mother to help).

7- Child completes clean-up without mother's assistance but not quickly. (There was time for mother to help.) This code may be used when experimenter instructions are directed toward the child and the parent demonstrates no involvement in setting the agenda or participating in the task. 


\section{Overall Ratings of Mother Behavior (continued)}

\section{Mother Supportive Presence (Emotional Climate)}

This is a global code that is used to determine the degree to which the mother provides an emotional climate that is supportive of completing the clean-up task, regardless of the effectiveness of her intervention. High scoring mothers are able to balance the child's desire for autonomous behavior with the provision of emotional support when difficulty or noncompliance is observed, while maintaining a generally positive tone of the interaction. Lower scoring mothers provide a less positive tone, and do not achieve a balance of providing support while respecting the child's autonomous behavior. Specific qualities to consider include: staying calm, maintaining task focus, mood setting, sharing positive affect, physical presence, supporting child's actions. anticipating frustration, and helping the child achieve a sense of reinforcement at having completed the task on his/her own. The general affective tone and emotional climate throughout the procedure should also be considered.

1. Mother is not supportive - she may be uninvolved or emotionally and overly harsh. The general emotional climate is disruptive of child behavior.

2. Mother provides minimal support, or there are periods where child behavior is disrupted because the mother does not provide sufficient or appropriate support. Mom may be overbright but unable to engage child emotionally in task.

3. Support is adequate, but there is no special joy in completing the task. The mother merely assists in getting the job done, but generally there isn't a positive consequence of having completed the task. There is a mix of positive and negative affective tone or neutral throughout.

4- Support is adequate for completing the task, and the mother has provided a somewhat positive environment in which the child can feel accomplished. The mother demonstrates primarily positive affect and offers some encouragement or positive feedback.

5. The mother's support is excellent in providing the child with a positive experience that promotes self-worth, learning, and fun in completing the task. The mother demonstrates consistently positive affect and provides encouragement so that the child can feel accomplished. Child may complete the task quickly and the mother may give child low level support but it is what the child needs.

6. Child completes the task very quickly without any support. 


\section{Overall Ratings of Mother Behavior (continued)}

\section{Level of Involvement}

This is a global scale used to determine who was physically responsible for any completion of the clean-up task. Specific behaviors to consider include who is more involved in the organization and putting of toys in basket.

1. There is no mother involvement in the completion of the clean-up task beyond providing verbal and emotional support for the child. Mother does not physically participate in clean-up task at all or the child is solely responsible for any completion of the task.

2. There is minimal participation by the mother in the clean-up task. The mother does some cleaning or assisting in moving toys closer to the box, but the child is responsible for the majority of the completion of the task. The child displays greater participation in the task than the mother.

3. The mother is involved in at least half or the majority of the completion of the clean-up task. She participates by moving toys closer to the box so child need only perform simple action of moving toys from the floor to the box, and/or mother puts away some or most of the toys. The child puts away no more than half the toys, providing largely perfunctory assistance. The mother displays as much or greater participation in the task than the child.

4- The mother is solely responsible for any completion of the clean-up task with no effective child involvement. The child does not participate in the actual process of putting toys in the box and any toys that are put away, the mother does on her own.

5• There is minimal attention to or focus on the clean-up. The clean-up task is abandoned or not completed. 


\section{APPENDIX 4 \\ Self-Concept Lower Order Dimensions}

5 Year Olds

\section{ACHIEVEMENT}

1A Ach1: I mostly do things that are hard.

11B Ach2: I care about doing a really good job on everything I do.

31A Ach4: I like hard work.

\section{AGRESSION}

2B Agg: When I get angry, I feel like hitting someone.

12B Agg2: Sometimes it's fun to scare people.

22A Agg3: I sometimes try to push in front of people in line.

32A Agg4: Sometimes I like to tease people by saying mean things to them.

42B Agg5: I like to watch people fight.

\section{ALIENATION}

23A Al3: When my friends come over to my house they play with my toys and not me.

33A Al4: Nobody wants to be around me.

43B Al5: People always say mean things to me.

\section{HARM-AVOIDANCE}

4B Ha1: I don't climb up on things that are high. 
14B Ha2: I don't think it would be fun at all to go down a slide head-first.

24A Ha3: I don't think that it would be fun to hang upside-down on a jungle-gym.

34A Ha4: When I hear lightening and thunder, I would never run to look out the window.

\section{SOCIAL CLOSENESS}

6B Sc1: I like to play with friends.

16A Sc2: I have a best friend.

26B Sc3: It's more fun to do things with other people than by myself.

36B Sc4: I am happiest when I'm around people.

46B Sc5: When I am sad, I go find someone to play with.

\section{SOCIAL POTENCY}

7B Sp1: I like to tell my friends what to do.

17B Sp2: I pick the game to play.

27A Sp3: I like to have people look at me.

37A Sp4: I am the leader in "follow the leader."

\section{STRESS REACTION}

8A Sr1: I get scared a lot.

18A Sr2: I get mad a lot.

38B Sr4: When I am scared, I have trouble falling asleep. 


\section{TRADITIONALISM}

9A Tr1: I never do things that I'm not supposed to do.

19A Tr2: I usually do what Mommy or the teacher says.

29B Tr3: I never get in trouble for being bad.

39A Tr4: I never do naughty things.

49B Tr5: I am a good girl/boy.

\section{WELL-BEING}

20B Wb2: When I'm happy, I feel good all over.

30B Wb3: I really like myself.

40B Wb4: I always feel great when I wake up in the morning. 


\section{BIBLIOGRAPHY}

Apolonio, F. J. (1975). "Preadolescent's self-esteem, sharing behavior, and perceptions of parental behavior". Dissertation Abstracts, 35, 3406B.

Baldwin, A. L., (1948). "Socialization and the parent-child relationship". Child Development, 19, 127-136.

Baumrind D., (1967). Genetic Psychological Monograph, 75, 43-88.

Baumrind, D. \& Black (1967). Child Development, 38, 291-328.

Baumrind, D. (1973). “The development of instrumental competence through socialization". In A. D. Pick (Ed.), Minnesota Symposia on Child Psychology (Vol. 7, pp. 3-46). Minneapolis: University of Minnesota Press.

Bowlby, J. (1969). Attachment and Loss: Vol.1. Attachment. Basic Books: New York.

Bowlby J. (1979). The Making and Breaking of Affectional Bonds. London: Tavistock.

Bretherton, I. (1990). "Open communication and internal working models: Their 
role in the development of attachment relationships". R. A. Thompson (Ed.), Nebraska Symposium on Motivation, 1988: Socioemotional Development. Current Theory and Research in Motivation, Vol. 36. University of Nebraska Press: Lincoln, NE.

Bretherton, I. (1991). "Pouring new wine into old bottles: The social self as internal working model". In M. R. Gunnar \& L. A. Sroufe (Eds.), Self Process and Development: The Minnesota Symposia on Child Development (Vol. 23 pp. 1-42). Hillsdale, NJ: Erlbaum.

Busch-Rossnagel, N. A., Knauf-Jensen, D. E., \& DesRosiers, F. S. (1995) In R. MacTurk \& G. Morgan (Eds.), Advances in Applied Developmental Psychology, Vol. 12. (pp. 117-145) Norwood, New Jersey: Ablex Publishing Co.

Cassidy, J. (1990). "Theoretical and methodological considerations in the study of attachment and the self in young children". In M. T. Greenberg, D. Cicchetti \& E. M. Cummings (Eds.), Attachment in the Preschool Years: Theory, Research and Intervention (pp.87-120) Chicago: University of Chicago Press.

Cicchetti, D. \& Beeghly, M. (1990). "Perspectives on the study of the self in transition". In D. Cicchetti \& M. Beeghly (Eds.), The Self in Transition: Infancy to Childhood (pp.1-15). Chicago: University of Chicago Press.

Comstock, M. L. C. (1973). "Effects of perceived parental behavior on self- 
esteem and adjustment". Dissertation Abstracts, 34, 465B.

Cooley C. H. (1902). Human Nature and the Social Order. New York: Charles Scribner's Sons.

Coopersmith, S. (1967). The Antecedents of Self-Esteem. San Francisco: Freeman.

Damon, W. \& Hart, D. (1982). "The development of self-understanding from infancy through adolescence". Child Development, 53, 841-864.

Eder, R. A., Gerlach, S. G., \& Perlmutter, M. (1987). "In search of children's selves: Development of the specific and general components of the self-concept". Child Development, 58, 1044-1050.

Eder, R. A. (1989). "The emergent personologist: The structure and content of 3 $1 / 2,51 / 2$ and $71 / 2$-year-old's concepts of themselves and other persons". Child Development, 60, 1218-1228.

Eder, R. A. (1990). “Uncovering young children's psychological selves: Individual and developmental differences". Child Development, 61, 849-863.

Eder, R. A. \& Mangelsdorf, S. C. (1997). "The emotional basis of early 
personality development: Implications for the emergent self-concept". In S. Briggs, R. Hogan \& W. Jones (Eds.), Handbook of Personality Psychology. Orlando, Florida: Academic Press.

Emde, R. N. (1988). "Development terminable and interminable: Innate and motivational factors from infancy". International Journal of Psychoanalysis, 69, 23-25.

Giusti, L., Mirsky, E., Seifer, R. \& Dickstein, S. (1997). “Clean-up task coding manual". Adapted from G. Kochanska \& T. Tjebkes, Child compliance/mother discipline project coding/entry manual (manuscript).

Harter, S. (1983). "Developmental perspectives on the self-system". In P. H. Mussen (Series Ed.) \& E. M. Hetherington (Vol. Ed.), Handbook of Child Psychology: Vol. 4. Social and Personality Development (4th ed., pp. 275-385). New York: Wiley.

Harter, S., \& Pike, R. (1984). "The pictorial scale of perceived directionality of the link between approval and self-worth: The liabilities of a looking glass self orientation among young adolescents". Journal of Adolescence, 6, 285-308.

Harter, S. (1998). "The development of self-representations". In W. Damon \& N. Eisenberg (Eds.), Handbook of Child Psychology: Vol. 3. Social, Emotional and Personality Development (5th ed., pp. 553-617). John Wiley and Sons, Inc.: New York. 
Hoffman, M. L. (1970). "Moral development". In P. H. Mussen (Ed.), Carmichael's Manual of Child Psychology: Vol. 2 (pp. 261-359). Wiley: New York.

Kochanska, G. (1991). "Socialization and temperament in the development of guilt and conscience". Child Development, 62, 1379-1392.

Kochanska, G. (1993). "Toward a synthesis of parental socialization and child temperament in early development of conscience". Child Development, 64, 325-347.

Kochanska, G. (1995). “Children's temperament, mother's discipline, and security of attachment: Multiple pathways to emerging internalization". Child Development, 66, 597-615.

Kochanska, G. \& Aksan, N. (1995). "Mother-child positive affect, the quality of child compliance to requests and prohibitions, and maternal control as correlates of early internalization". Child Development, 66, 236-254.

Kochanska, G., Padavich, D.L. \& Koenig, A.L. (1996). “Children's narratives about hypothetical moral dilemmas and objective measures of their conscience: mutual relations and socialization antecedents". Child Development, 67, 1420-1436.

Kuczynski, L., Kochanska, G., Radke-Yarrow, M., \& Girnius-Brown, O. (1987). "A developmental interpretation of young children's noncompliance". Developmental 
Psychology, 23, 799-806.

Lepper, M.R. (1981). "Intrinsic and extrinsic motivation in children: detrimental effects of superfluous social controls". In N.A. Collins (Ed.) Minnesota Symposia on Child Psychology, (pp.155-214). University of Minnesota Press: Minneapolis.

Loeb, R. C., Horst, L. \& Horton, P. J., (1980). "Family interaction patterns associated with self-esteem in preadolescent girls and boys". Merrill-Palmer Quarterly, $26,203-217$

Maccoby, E. (1980). Social development. New York: Wiley.

Maccoby, E.E. \& Martin, J.A. (1983). "Socialization in the context of the family: Parent-child interaction". In P. Mussen (Series Ed.) \& E.M. Hetherington (Ed.), Socialization, Personality, and Social Development: Vol.4. Handbook of Child Psychology (4th ed., pp. 1-102). Wiley: New York.

Matas, L., Arend, R.A. \& Sroufe, L.A. (1978). "Continuity of adaptation in the second year: The relationship between quality of attachment and later competence". Child Development, 49, 547-556.

Messer, S. B. \& Yarrow, L. J. (1983). "Assessment of mastery motivation 
during the first year of life: Contemporaneous and cross-age relationships". Developmental Psychology, 19, 159-171.

Mondell, S. \& Tyler, F. B. (1981). "Parental competence and styles of problem solving/play behavior with children". Developmental Psychology, 17, 73-78.

Piaget, J. (1932). The moral judgment of the child. New York: Harcourt, Brace \& World.

Qadri, A. J. \& Kaleem, G. A. (1971). "Effect of parental attitudes on personality adjustment and self-esteem of children". Behaviorometric, 1, 19-24.

Radke (1946). “The relation of parental authority to children's behavior and attitudes". University of Minnesota Institute of Child Welfare Monograph, 22.

Sears, R.R. (1963). "The relation of early socialization experiences to aggression in middle childhood". Journal of Abnormal Social Psychology, 63, 466-492.

Sears R.R., Whiting, J.W.M., Nowlis,V., \& Sears, P.S. (1953). "Some childrearing antecedents of aggression and dependency in young children". Genetic Psychology Monogram, 47, 135-234.

Seifer, R. (1998). Personal communication. 
Seifer, R., Sameroff, A., Barrett, L. \& Krafchuk, E. (1994). "Infant temperament measured by multiple observations and mother report". Child Development, 65, 1478-1490.

Seifer, R. \& Vaughn, B. (1995). "Mastery motivation within a general organizational model of competence". In R. MacTurk \& G. Morgan (Eds.), Advances in Applied Developmental Psychology, Vol. 12. Norwood, New Jersey: Ablex Publishing Co.

Seifer, R., Schiller, M., Sameroff,A., Resnick, S., \& Riordan, K. “Attachment, maternal sensitivity, and temperament during the first year of life". Developmental Psychology (in press).

Sroufe, L. A. (1979). "Socioemotional development". In J. Osofsky (Ed.), Handbook of Infant Development. New York: Wiley.

Sroufe, L. A., Fox, N., \& Pancake, V. (1983). "Attachment and dependency in developmental perspective”. Child Development, 54, 1615-1627.

Sroufe, L. A. (1990). "An organizational perspective on the self". In D. Cicchetti \& M. Beeghly (Eds.), The Self in Transition: Infancy to Childhood (pp. 281308). Chicago: University of Chicago Press. 
White, R. (1959). "Motivation reconsidered: The concept of competence". Psychological Review, 66, 297-333.

Winnicott, D. W. (1958). From Peadiatrics to Psychoanalysis. London: Hogarth Press. 